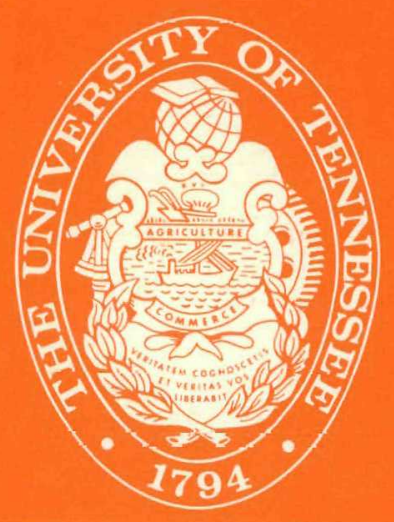

\title{
ELECTRICAL
}

ENGINEERING

DEPARTMENT

\section{UNIVERSITY OF TENNESSEE}

MASTER

\author{
KNOXVILLE \\ TN 37916
}




\section{DISCLAIMER}

This report was prepared as an account of work sponsored by an agency of the United States Government. Neither the United States Government nor any agency Thereof, nor any of their employees, makes any warranty, express or implied, or assumes any legal liability or responsibility for the accuracy, completeness, or usefulness of any information, apparatus, product, or process disclosed, or represents that its use would not infringe privately owned rights. Reference herein to any specific commercial product, process, or service by trade name, trademark, manufacturer, or otherwise does not necessarily constitute or imply its endorsement, recommendation, or favoring by the United States Government or any agency thereof. The views and opinions of authors expressed herein do not necessarily state or reflect those of the United States Government or any agency thereof. 


\section{DISCLAIMER}

Portions of this document may be illegible in electronic image products. Images are produced from the best available original document. 
Printed in the United States of America. Available from the Department of Energy

Technical Information Center

P.Q. Box 62, Oak Ridge, Tennessee 37830

Printed Copy $\mathrm{AO}_{4}$; Microfiche A01

This report was prepared as an account of work sponsored by the United States Government. Neither the United States nor the Department of Energy, nor any of their employees, nor any of their contractors, subcontractors, or their employees, makes any warranty, express or implied, or assumes any legal liability or responsibility for the accuracy, completeness or usefulness of any information, apparatus, products disclosed, or represents that its use would not infringe privately owned rights. 
Work Performed By

The University of Tennessee

Electrical Engineering Department

Knoxville, Tennessee 37916

Second Year Contract Report

Subcontract Number 7685

Project Authorization X32

RESEARCH IN REMOTE SIGNIAL

TRANSMISSI ON ELECTRONICS

Report II

E. J. Kennedy, T. V. Blalock

S. Genther, P. Mukund, H. Orrick

October 1, 1980

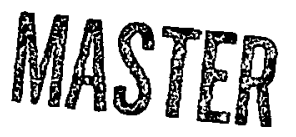

for

OAK RIDGE NATIONAL LABORATORY

Oak Ridge, Tennessee 37830

Operated By

UNION CARBIDE CORPORATION

for the

ENERGY RESEARCH AND DEVELOPMENT ADMINISTRATION

Contract No. W-7405-eng-26

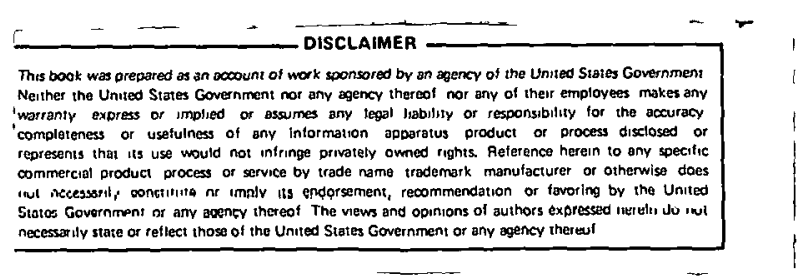




\section{TABLE OF CONTENTS}

CHAPTER

PAGE

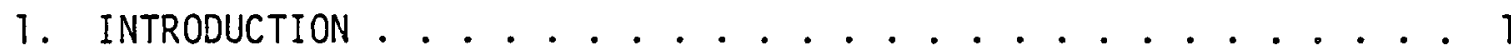

2. DC-DC CONVERTER II FOR $230^{\circ} \mathrm{C}$ OPERATION . . . . . . . . 3

Introduction . . . . . . . . . . . . . . . . . . 3

Design Theory and Considerations . . . . . . . . . . 3

Evolution of the Converter II Circuit . . . . . . . 3

Switching Regulator ................. 7

Multivibrator Design .. . . . . . . . . . . . . 9

Start-Up Considerations .............. 13

Loop Transmission of the Converter . . . . . . . . 15

Other Design Considerations . . . . . . . . . . 17

Experimental Results.................. . 19

Operation with the Simulated Isotopic Supply . . . . . . 20

Operation with a Variable Input Supply Voltage . . . . . 28

Converter Start-Up . . . . . . . . . . . . . 30

3. AMPLIFIER-DISCRIMINATOR CIRCUITS FOR $230^{\circ} \mathrm{C}$ OPERATION . . . . . 34

Introduction ..................... 34

Op Amp Circuit TT . . . . . . . . . . . . . . . 34

Circuit II Characteristics............. . 34

Op Amp Circuit III . . . . . . . . . . . . . . . 37

Circuit III Design Details............... 39

Circuit III Construction and Operation . . . . . . . . 44

Summary ...................... 47

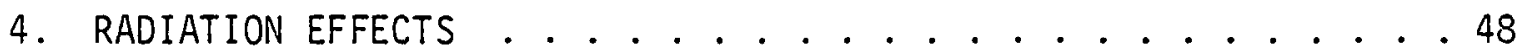

Introduction ..................... . 48 
Theory . . . . . . . . . . . . . . . . . . 49

Radiation Tests ................ 50

Test Results..................... 51

Bipolar Transistors .. . . . . . . . . . . 51

JFETS ....................... . . 51

VMOS Transistors ................... . 52

Operational Amplifiers . . . . . . . . . . . . . 52

Thick-Film Resistor Inks............... 53

Other Devices ................... 53

Summary ........................ 54

5. MISCELLANEOUS RESEARCH . . . . . . . . . . . . . . 55

Introduction . . . . . . . . . . . . . . . 55

Capacitor Tests .................. . . 55

Comparisons of Aluminum Wire for High-Temperature

Ultrasonic Bonds ................ 57

Computer Programs for High-Temperature Simulations . . . . . . 58

Silver Migration and Solderability of Various Thick-Film

Conductors .................... 59

LIST OF REFERENCES . . . . . . . . . . . . . . . . 62 


\section{LIST OF FIGURES}

FIGURE

PAGE

2-1. Converter II Circuit For $230^{\circ} \mathrm{C}$ Operation ......... . 5

2-2. Multivibrator Timing Circuits . . . . . . . . . . . 9

2-3. Op Amp Output Voltage as a Function of Temperature and Supply Voltage (calculated from Eq. 2-14) . . . . . 12

2-4. Frequency of Multivibrator as a Function of Battery Voltage and Temperature.............. 22

2-5. Total Efficiency of the DC to DC Converter as a Function of Battery Voltage and Temperature . . . . . . 24

2-6. Power Losses as a Function of Temperature . . . . . . . . 25

2-7. Efficiency of the Switching Regulator as a Function of Battery Voltage and Temperature ........... . 26

2-8. Error Amplifier Output Voltage as a Function of Battery Voltage and Temperature ............ 27

2-9. Positive Regulated Output Voltage as a Function of Battery Voltage and Temperature ............ 29

2-10. Battery Current as a Function of Battery Voltage and Temperature.................. 31

2-11. Duty Cycle as a Function of Battery Voltage for $\mathrm{T}=25^{\circ} \mathrm{C}$ and $\mathrm{T}=230^{\circ} \mathrm{C}$. . . . . . . . . . . 32

3-1. Schematic Diagram of Op Amp Circuit II . . . . . . . . . 35

3-2. Thick-Film Layout of the Quad 0p Amp Circuit III . . . . . . . 36

3-3. Signal Response Characteristics of Circuit II . . . . . . . 38

3-4. Schematic Diagram of Op Amp Circuit III . . . . . . . . . . . 40

3-5. Output Signal Voltage and Currents for the Driver Stage of $Q_{1}-Q_{2}$, with $C_{L}=490 \mathrm{pF}$............ 43

3-6. Thick-Film Hybrid Layout for Op Amp Circuit III . . . . . . . 45

3-7. Circuit Test Board for Circuit III . . . . . . . . . . 46

5-1. Long-Term Test Data for "Kemet" Tantalum Capacitors

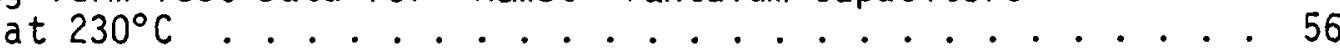




\section{LIST OF TABLES}

TABLE

PAGE

2.1 P-N Junction Voltages for Multivibrator Analysis . . . . . . 10

2.2 Measured Typical Operating Points and Performance Specifications of DC to DC Converter II with

Simulated Isotopic Supply........ 


\section{ABSTRACT}

Research has been directed toward the evaluation of semiconductor circuits suitable for operation at temperatures of $230^{\circ} \mathrm{C}$. These circuits are to be utilized in monitoring neutron flux for initial fuel loading in a breeder reactor. Two new amplifier circuits were developed and tested, as well as new concepts for a high current driver circuit and a temperature-stable discriminator-multivibrator circuit. An improved $d c-d c$ converter circuit was constructed and evaluated at $230^{\circ} \mathrm{C}$. Initial data was obtained on radiation effects on discrete devices, integrated circuits, resistors, and capacitors, for possible use in fuel reloading requirements. 
CHAPTER I

INTRODUCTION

This report covers work performed for the Oak Ridge National Laboratory (ORNL) by the University of Tennessee, Knoxville, (UTK) Electrical Engineering Department during the period from Oct. 1, 1979 to Sept. 30, 1980. This work is a continuation of the effort reported

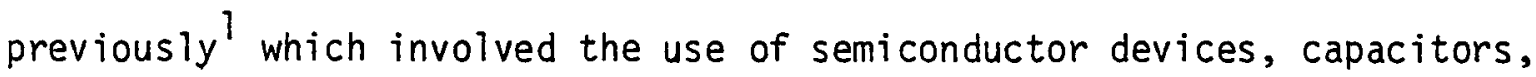
resistors and other materials and components, in circuits for operation at temperatures up to $300^{\circ} \mathrm{C}$ for time periods as long as $2000 \mathrm{hrs}$. The circuits are to be used for remote monitoring of core neutrons during the initial loading of Liquid Metal Fast Breeder Reactors (LMFBR) and must, therefore, be components of an in-vessel system (no penetration of reactor housing) installet at the start of core loading and remaining in place in a sodium pool until the final phase of the loading sequence.

The reduction of the system operating temperature specification from the $250^{\circ} \mathrm{C}-300^{\circ} \mathrm{C}$ environment of last years contract work to a $200^{\circ} \mathrm{C}-230^{\circ} \mathrm{C}$ range for this years effort caused a number of additional circuits to become candidates for use in high-temperature remote signal transmission electronics. Perhaps the most important additional circuit was the monolithic dielectrically isolated operational amplifier which could be used to improve several circuits developed last year.

A second-generation dc-dc converter using the Harris dielectrically isolated operational amplifier is reported in Chapter 2. The operational amplifiers were also used in two designs of the amplifier-discriminator circuits which are reported in Chapter 3 . Chapter 4 presents some preliminary results from radiation tests on several semiconductor devices 
used in circuits developed over the past two years of activity. Some miscellaneous research is reported in Chapter 5 which includes hightemperature studies on capacitors, thick-film bonding tests, computer simulations of high temperature circuit operation, and solderability studies for thick-film systems. 
CHAPTER 2

DC-DC CONVERTER II FOR $230^{\circ} \mathrm{C}$ OPERATION

\subsection{INTRODUCTION}

A new dc-dc converter was developed to operate at the lowered temperature requirement (from $300^{\circ} \mathrm{C}$ to $230^{\circ} \mathrm{C}$ ) for the remote signal transmission electronics. The lower temperature allowed use of the Harris dielectrically isolated operational amplifier in the converter loop with a consequent simplification of the circuit and the feasibility of improving the operating characteristics beyond those of last years design. Design constraints were further eased by the nearly constant converter input voltage provided by the zener-diode regulated isotopic power supply. This reduced range of input power supply variation permitted a simplified duty-cycle control technique. The availability of large value $\left(10_{\mu} \mathrm{F}\right)$ capacitors for the $230^{\circ} \mathrm{C}$ operation allowed simplification and improvement of the switching regulator output ripple filter.

The next part of this section presents the design evolution, the theoretical relationships necessary for design optimization, and the considerations germane to the implementation of Converter II. The last part of this section reports the experimental results of tests on Converter II.

\subsection{DESIGN THEORY AND CONSIDERATIONS}

\section{2-1 Evolution of the Converter II Circuit}

The first converter circuit considered used a quad op-amp chip and was a conventional design with a comparator type clock circuit with frequency essentially independent of duty cycle (this was not the 
case for Converter I developed last year). We considered the constant frequency operation and the simple single-chip implementation of the regulator electronics to be a significant improvement over the $300^{\circ} \mathrm{C}$ circuit of last year. However, experimental studies of this circuit showed serious problems due to long delay and rise times, soft saturation properties, and dynamic range limitations. Furthermore, the poor drive capability of the op-amp chip required a complementary and perhaps a regenerative buffer to drive the VMOS switch. The design evolution of such a buffer resulted in a circuit basically the same as the multivibrator used in Converter I.

The second converter circuit considered, therefore, used the Converter I multivibrator-driver circuit, 1 had the darlington differential pair replaced by a single differential pair, and employed a single HA2625 op amp operating as an integrator to provide very high low-frequency loop transmission with an active dominant pole determined by a capacitor of reasonable value. Preliminary studies of this converter indicate that it would be a strong second generation candidate for $300^{\circ} \mathrm{C}$ operation when a $300^{\circ} \mathrm{C}$ op amp becomes available. It has significantly superior performance over the Converter I of last year.

Due to the small expected variation of the input voltage, $V_{B}$, a third converter circuit can be designed by simplifying the second circuit discussed above. The differential pair which controls the multivibrator charging current was replaced by a simple resistance network connected directly between the op amp output and the base of one of the four bipolar transistors in the multivibrator circuit as shown in Fig. 2-1. This circuit has a lower loop gain than the differential 


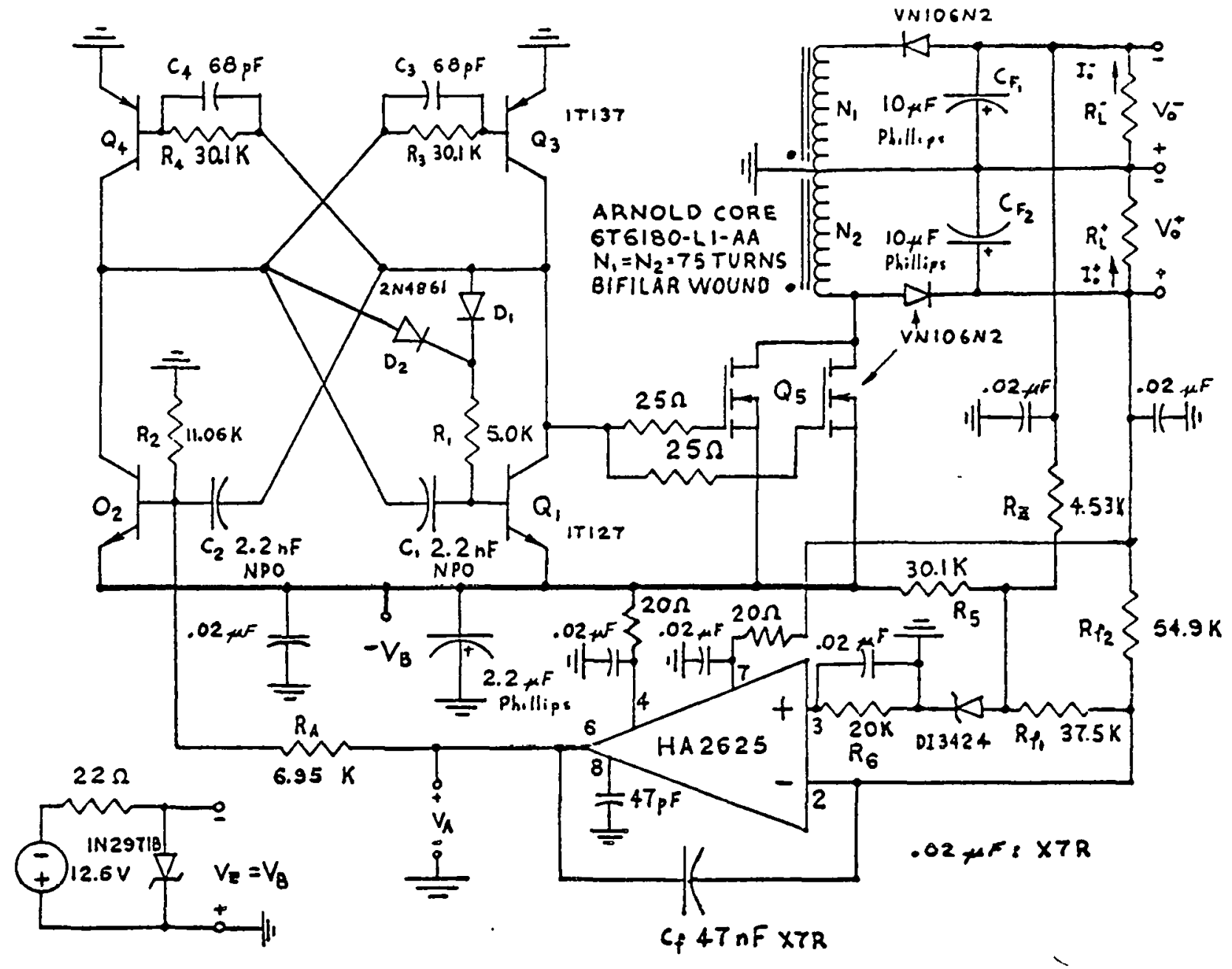

Fig. 2-1. Converter II Circuit for $230^{\circ} \mathrm{C}$ Operation

pair circuit and could therefore be stabilized for low values of capacitance and reasonable values of input resistance of the error amplifier. The charging time of $C_{1}\left(Q_{1}\right.$ off $)$ represents the on time, $T_{1}$, of the VMOS switch and is independent of duty cycle. The charging time, $T_{2}$, of $C_{2}\left(Q_{2}\right.$ off $)$ is the off time of the VMOS switch and is changed by varying the Thevenin charging voltage which is directly related to $V_{A}$ (Fig. 2-1). In this way, with fixed on-time and variable off-time the duty cycle can be adjusted to regulate the output voltage.

This timing scheme is only useful if the required change in duty cycle, 
$D$, is small. Large changes in duty cycle would produce wide variations in operating frequency. Also the greater the variation in duty cycle the greater the variation in $V_{A}$ required; however, the sma11 expected variation in $V_{B}$ can be accomodated by the dynamic range of $V_{A}$. Note that due to the timing arrangement, as $V_{B}$ increases with temperature, the required duty cycle decreases, which requires $T_{2}$ to increase and decrease the frequency ( $T_{1}$ constant with $\left.D\right)$. This tends to offset effects which increase frequency with temperature such as charge removal.

The configuration of Fig. 2-1 was used in the final design; however, the multivibrator could be rearranged by interchanging the role of NPN and PNP transistor pairs. This arrangement was breadboarded and was found to have faster transients than the Fig. 2-1 arrangement; however, dynamic range and base drive considerations made the latter circuit more practical. In this circuit as $V_{B}$ becomes more negative, $v_{A}$ must become more negative to maintain constant output voltage. Thus, the output dynamic range of the op-amp is improved as needed. In the al ternate circuit (PNP, NPN exchanged), $V_{B}$ and $V_{A}$ changes reduced $\left|V_{B}\right|-\left|V_{A}\right|$ causing reduced output range. Also, the alternate circuit had greater variations of base drive currents with $V_{A}$ since the charging voltage was near the switching voltage at some points requiring a small equivalent charging resistance. If proper drive were established for high $V_{A}$ it would be excessive for low $V_{A}$. This problem was not as severe with the Fig. 2-1 arrangement.

Another advantage of the type of duty cycle control used in the Fig. 2-1 circuit is that the duty cycle range is 1 imited by the dynamic range of $V_{A}$ which must be between $-\left|V_{B}\right|$ and $V_{0}+(F i g .2-1)$. This guarantees a minimum output if $V_{A}$ saturates low which, as will be seen 
later, guarantees startup and limits startup current when $\mathrm{V}_{0}^{+}$and $\mathrm{V}_{0}^{-}$are low. The maximum duty cycle is limited by $v_{0}^{+}$. When $v_{A}$ saturates high, it cannot further increase until $\mathrm{V}_{0}^{+}$increases, thus, controlling startup and reducing the current required. This situation is analyzed later to insure that the output will increase up to $+10 \mathrm{~V}$ and not be limited to some lower output voltage.

The Zener reference supply $v_{r}$ is biased from the regulated output $v_{0}{ }^{-}$. The $v_{r}=-6.9 \mathrm{~V}$ reference is used to regulate the positive output by placing a divider between $V_{0}^{+}$and $V_{r}$ and comparing the divider output to ground (Fig. 2-1). The referencing is done this way to keep the op amp inputs within the common mode range without dividing down the $-6.9 \mathrm{~V}$ reference.

Biasing the reference from the $v_{0}^{-}$supply complicates the converter start-up. The bias circuit.is arranged so that the op amp inverting input is held negative until the reference zener comes into regulation; this assures adequate duty cycle for start-up. The line-and load-regulation are reduced by the reference arrangement because of series resistance in the output voltage lines and also because of the rather high dynamic impedance (100-200 $\Omega$ ) of the reference device. The regulation obtained, however, is sufficient for our requirements. A major advantage of using the regulated outputs for reference biasing is the elimination of possible transients on the $V_{B}$ line generated by the acoustic transducer drive circuit.

\section{2-2 Switching Regulator}

The switching regulator used in the Converter II design of Fig. 2-1 is identical to that of last year's Converter I except the output 
filter has been simplified by use of the 10uF Phillips solid electrolytic capacitors instead of the $\pi$ section filter using a series inductor. A detailed analysis of the switching regulator was presented in the 1979 report ${ }^{1}$ from which some results will be quoted here as needed.

The duty cycle which is defined as

$$
0=\frac{T_{1}}{T_{1}+T_{2}}
$$

is related to the converter voltages by

$$
v_{0}+v_{D}=v_{B}^{\prime}\left(\frac{D}{T-D}\right)
$$

where $T_{1}$ is the switch "On" time, $T_{2}$ is the switch "Off" time, $V_{B}^{\prime}$ is the effective supply voltage, $V_{D}$ is an average rectifier forward voltage drop, and $V_{0}$ is the sampled output voltage. By combining Eqs. (2-1) and $(2-2)$ a more convenient expression for our purposes is obtained:

$$
\frac{V_{0}+V_{0}}{V_{B}{ }^{T}}=\frac{T_{1}}{T_{2}}
$$

The basic operation of the switching regular can be explained in the following way; During the "On" time of the VMOS switch, enerqy is stored in the transformer core by a current flowing from ground potential, through one-half of the transformer winding, through the VMOS channel, and the into the negative input voltage $V_{B}$. During the VMOS "Off" time, a portion of the stored energy is dumped through the rectifier diodes into the output filter and load by transformer "flyback" action governed by the well-known relationship $V=L d i / d t$. The two transformer windings are bifilar wound so that the negative unregulated output voltage will closely track the regulated positive output voltage. 


\section{2-3 Multivibrator Design}

The multivibrator frequency and duty cycle are determined by the capacitor charging times $T_{1}$ and $T_{2}$ which can be calculated by analys is of the charging circuits of Fig. 2-2.

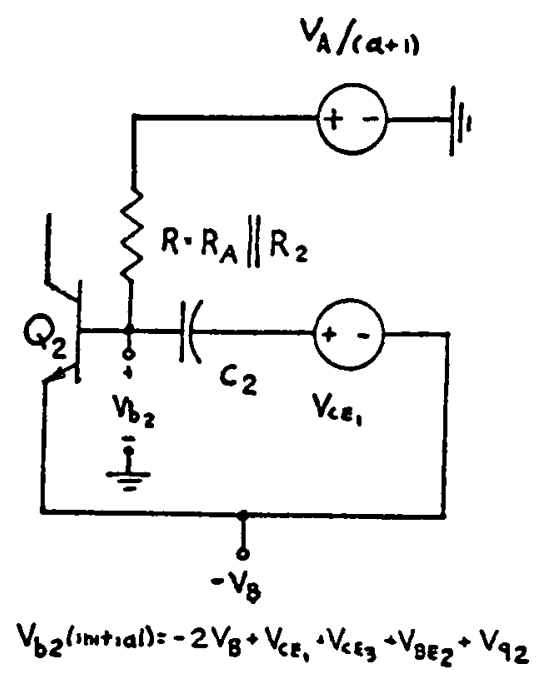

(a) $T_{2}$ : switch off time

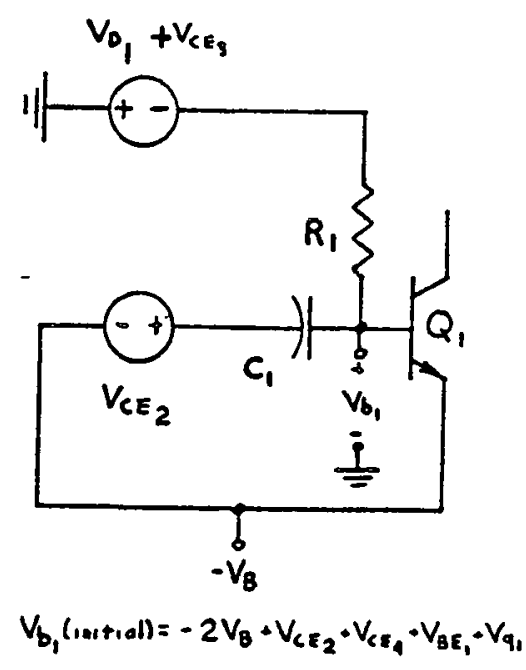

(b) $T_{7}$ : switch on time

Fig. 2-2. Multivibrator Timing Circuits.

The general expression for a node voltage controlled by a single RC time-constant is

$$
V(t)=V_{F}-\left(V_{F}-V_{I}\right) \varepsilon^{-\frac{t}{R C}}
$$

where $V_{F}$ is the final $(t \rightarrow \infty)$ node voltage and $V_{I}(t \rightarrow 0)$ is the initial node voltage. The time $T$ for a node voltage to reach some switching value $V_{S}$ is then given by

$$
T=R C \ln \left(\frac{V_{F}-V_{I}}{V_{F}-V_{S}}\right) .
$$

Analysis of the charging circuits using Eq. (2-5) leads to the following 
expressions for the charging times:

$$
\begin{aligned}
& T_{1}=R_{1} C_{1} \ln \left[\frac{2 V_{B}-\phi_{1}}{V_{B}-\phi_{2}}\right], \\
& T_{2}=R C_{2} \ln \left[\frac{\frac{A}{a+1}+2 V_{B}-\phi_{3}}{\frac{V_{A}}{a+1}+V_{B}-\phi_{4}}\right],
\end{aligned}
$$

where

$$
\begin{aligned}
& \phi_{1}=v_{C E 2}+v_{C E 3}+v_{C E 4}+v_{B E 1}+v_{D 1}+v_{q 1}, \\
& \phi_{2}=v_{D 1}+v_{C E 3}+v_{01} \\
& \phi_{3}=v_{C E 1}+v_{C E 3}+v_{B E 2}+v_{Q 2} \\
& \phi_{4}=v_{\sigma 2} .
\end{aligned}
$$

The collector-emitter saturation voltages $V_{C E}$, the base-emitter saturation voltages $V_{B E}$, the base-emitter cut-in voltages $V_{\sigma}$, the diode voltage $V_{D 1}$ the rectifier forward voltage drop $V_{D}$; and the charge removal voltages $V_{q}$ are given in Tahle 2-1 at the two temperatures of interest. The

Table 2.1

P-N JUNCTION VOLTAGES FOR MULTIVIBRATOR ANALYSIS

$\begin{array}{ccc}\text { Voltage } & \frac{V \text { at } 25^{\circ} \mathrm{C}}{2} & \text { V at } 230^{\circ} \mathrm{C} \\ V_{C E} & 0.02 & 0.02 \\ V_{B E} & 0.8 & 0.5 \\ V_{D I} & 0.7 & 0.4 \\ V_{q} & 2.4 & 3.0 \\ V_{\sigma} & 0.65 & 0.3 \\ V_{D} & 0.65 & 0.3\end{array}$


constant $a$ is defined as the ratio of $R_{A}$ to $R_{2}$ (Fig. 2-1).

The duty cycle is varied by changes in voltage $V_{A}$ which in turn changes the time $T_{2}$ in Eq. (2-7). The frequency of the multivibrator is related to the time $T_{1}$ and the duty cycle by

$$
f=\frac{D}{T_{1}} \text {, }
$$

which is obtained from Eq. $(2-1)$. For the Fig. 2-1 circuit, $f$ was chosen to be $30 \mathrm{kHz}$ for $V_{B}=7.5 \mathrm{~V}$ at a temperature of $25^{\circ} \mathrm{C}$.

The constant a can be determined by writing timing equations for two sets of values for $V_{A}, V_{B}$ and the temperature $T$. The sets used were $V_{B}=6.5 \mathrm{~V}, V_{A}=3.0 \mathrm{~V}, T=25^{\circ} \mathrm{C}$; and $V_{B}=9.5 \mathrm{~V}, V_{A}=-2.0 \mathrm{~V}, T=230^{\circ} \mathrm{C}$. The range of $V_{B}$ was chosen larger than the expected range $(7.5$ to $8.25 \mathrm{~V})$ and the range of $V_{A}$ was set to be well within the saturation limits of the op amp. Equations (2-3), (2-6) and (2-7) can be written for the two sets of conditions above and combined to find $a=0.628$. With this value of $a$, the resistors $R_{A}$ and $R_{2}$ can be determined after $R=R_{A}|| R_{2}$ has been found from Eq. (2-7). The calculation of $R$ from Equation (2-7) of course requires knowledge of the supply voltage $V_{B}$, the value of the multivibrator frequency, the temperature, and the duty cycle.

From Eqs. $(2-3),(2-6)$, and $(2-7), \mathrm{V}_{0}^{+}$can be expressed as a function of $V_{A}$ and $V_{B}$ at a given temperature:

$$
V_{0}^{+}=V_{B} \frac{R_{1} C_{1} \ln \left[\frac{2 V_{B}-\phi_{1}}{V_{B}-\phi_{2}}\right]}{R C_{2} \ln \left[\frac{\frac{V_{A}}{a+1}+2 V_{B}-\phi_{3}}{\frac{V_{A}}{a+1}+V_{B}-\phi_{1}}\right]}-V_{D} .
$$


This result is useful for investigating multivibrator start-up and system loop transmission.

Equation $(2-13)$ can be solved for $V_{A}$ to give

$$
V_{A}=\frac{(a+1)\left[2 V_{B}-\phi_{3}-\left(V_{B}-\phi_{4}\right) \varepsilon^{x}\right]}{\varepsilon^{x}-1}
$$

where

$$
x=\frac{R_{1} C_{1} V_{B}}{R C_{2}\left(V_{0}^{+}+V_{D}\right)} \ln \left[\frac{2 V_{B}-\phi_{1}}{V_{B}-\phi_{2}}\right]
$$

For the component values in the circuit of Fig. 2-1, $V_{A}$ required for $\mathrm{V}_{0}^{+}=10 \mathrm{~V}$ is shown in Fig. $2-3$ for two values of temperature, $25^{\circ} \mathrm{C}$ and $230^{\circ} \mathrm{C}$. It is interesting to note that $V_{A}$ is almost a linear function of $V_{B}$ in the expected range of operation.

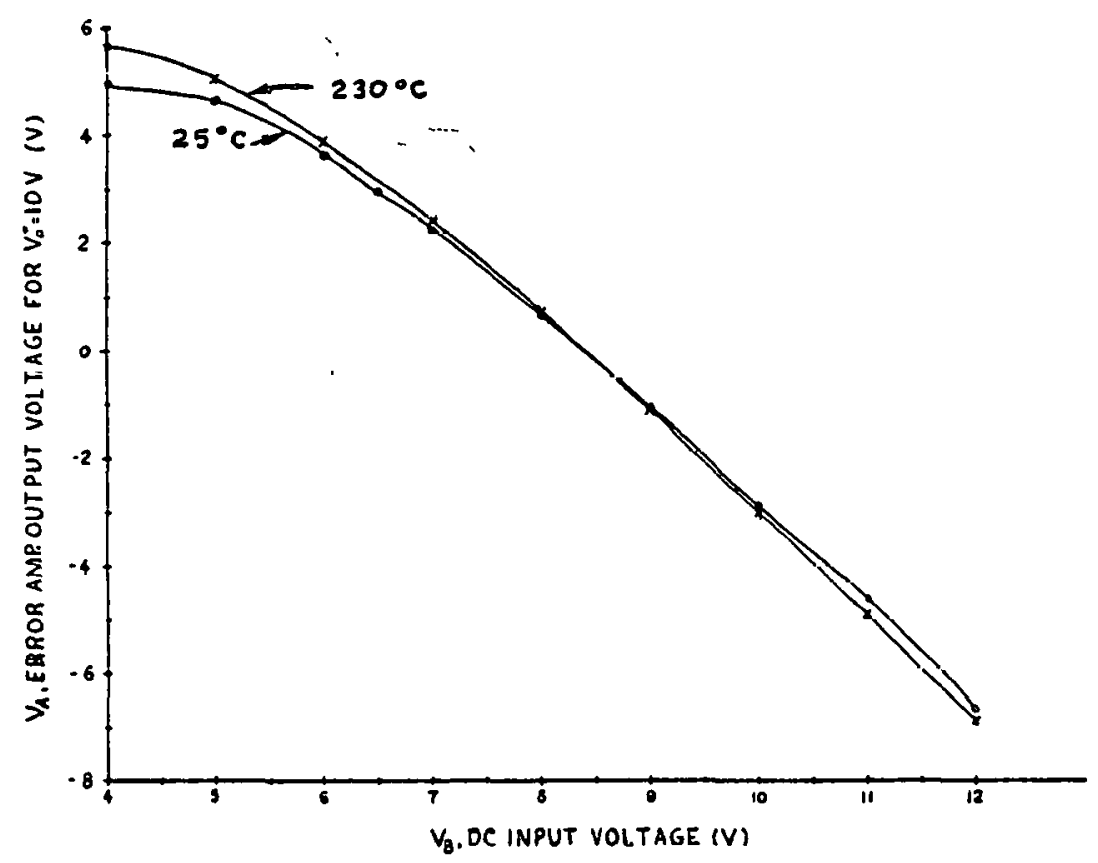

Fig. 2-3. Op Amp Output Voltage as a Function of Temperature and Supply Voltage (calculated from Eq: $2-14)$. 
The design of the multivibrator is completed by choosing the values of the timing capacitors $C_{1}$ and $C_{2}$ (Fig. 2-1) which then allows calculation of $R$ and $R_{1}$ from frequency considerations. Because of the wide temperature range $\left(25^{\circ} \mathrm{C}\right.$ to $\left.230^{\circ} \mathrm{C}\right)$ of operation, $C_{1}$ and $C_{2}$ were selected to have values large enough to minimize the charge removal effects ${ }^{l}$ but small enough to keep reasonable power dissipation in the multivibrator circuit. The values shown in Fig. 2-1 allow 1 to $2 \mathrm{~mA}$ of transistor base drive current during the switching times.

The resistors $R_{3}$ and $R_{4}$ were chosen to make both $I_{B I} / I_{B 3} \geq 4$ and $I_{B 2} / I_{B 4} \geq 4$ to insure that $Q_{1}$ and $Q_{2}$ can pull $Q_{3}$ and $Q_{4}$ out of saturation. The base drive ratio $I_{B 2} / I_{B 4}$ must be checked for $V_{A}$ saturated low to assure multivibrator start-up for this worst-case condition.

\section{2-4 Start-up Considerations}

Start-up is complicated by the fact that the error amplifier and reference are biased from the regulated outputs which are zero just before the power is turned on. However, it can be shown that this circuit will always come up to operating voltage if the multivibrator is running.

To assure start-up the error amplifier must call for a greater output voltage than is present until the output comes close to lov. To show that this occurs, first consider that $V_{A}$ is saturated at its low level which is the worst case condition. As previously mentioned, the smallest duty cycle is limited so there will always be a minimum output voltage. This minimum output voltage, $V_{\text {omin }}^{+}$, is calculated from Eq. (2-13) assuming $V_{A}=-V_{B}$. Worst case occurs for the smallest value of $V_{B}(6.5$ Volts $)$ which gives $V_{\text {omin }}^{+}=3$ volts. Three volts is sufficient to cause $V_{A}$ to saturate high and call for maximum output. 
A minimum output voltage is necessary because measurements on the saturation characteristics of the HA2625 op amp showed that the output will saturate low if the noninverting input is greater than 1.5 volts below the positive supply which is the situation when the convertor comes on. The $3 \mathrm{~V}$ minimum output voltage assures that the error amp will behave in the proper manner to call for maximum duty cycle.

With the op amp biased to saturate properly, its inputs must drive the amplifier output high if $\mathrm{V}_{0}^{+}$is too low. The noninverting input is grounded so the inverting input must be kept negative until the circuit comes into regulation. If $\mathrm{V}_{0}^{-}$is too small, the reference is off and what appears at the inverting input is a negative voltage which is a fraction of $\mathrm{V}_{0}^{-}$assuming $\mathrm{V}_{0}^{+}$and $\mathrm{V}_{0}^{-}$track. The resistor $\mathrm{R} 5$ connected to $-V_{B}$ pulls the inverting input more negative when $V_{0}^{+}$and $V_{0}^{-}$are small and provides additional assurance that the error amp will saturate high.

Since $V_{A}$ will eventually saturate high in the start-up condition, it must next be determined whether or not this value of $V_{A}$ will be high enough to bring up the output voltages since the positive supply for the op amp is $\mathrm{V}_{0}^{+}$. This is done by using Eq. (2-13) to determine if there exists an output voltage which will not allow $V_{A}$ to be high enough to call for a greater output. The Eq. (2-13) shows that, even for the pessimistic assumption that the op amp output voltage saturates $5 \mathrm{~V}$ below $V_{0}^{+}$, the output called for is greater than the present output for all values of $\mathrm{V}_{0}^{+}$during start-up; thus, $\mathrm{v}_{0}^{+}$and $\mathrm{V}_{0}^{-}$will come up until the reference turns on and the circuit comes into regulation. 
The limit on duty cycle imposed by the saturation of the op amp output voltage $V_{A}$ has the salutary effect of reducing the transient start-up current. Other configurations allow start-up duty cycles near unity unless special clamping circuits are incorporated to limit duty cycle.

\section{2-5 Loop Transmission of the Converter}

The loop transmission can be determined by considering the transfer function of each of two cascaded sections: (1) the transfer $V_{A} / N_{0}{ }^{+}$ through the error amplifier from the converter output to the op amp output; (2) the transfer $V_{0}^{+} / V_{A}$ from the op amp output to the converter output $V_{0}^{+}$.

The transfer function for the error amplifier is given by

$$
\frac{V_{A}}{V_{0}^{+}}=\left(\frac{R_{f 1}}{R_{f 1}+R_{f 2}}\right) \frac{-k}{\left(1-\frac{f^{2}}{f_{d} f_{1}}\right)+j f\left(\frac{k}{f_{1}}+\frac{1}{f_{d}}\right)} \text {, }
$$

where $k$ is the open loop $d c$ gain of the op amp, $f_{d}$ is the critical frequency associated with the dominant pole of the op amp, and the critical frequency $f_{f}$ is given by

$$
f_{1}=\frac{1}{2 \pi C_{f}\left(\frac{R_{f 1} R_{f 2}}{R_{f 1}+R_{f 2}}\right)} \text {. }
$$

In the frequency range for system stability studies, the error amplifier transfer function is adequately approximated by 


$$
\frac{V_{A}}{V_{0}} \approx-\frac{1}{2 \pi R_{f 2} C_{f}}\left(\frac{1}{j f}\right),
$$

which is the transfer function of a pure integrator.

The transfer function $V_{0}^{+} / N_{A}$ for small signals can be approximated at low frequencies by the partial derivative $2 V_{0}{ }^{+} / \partial V_{A}$ determined from Eq. $(2-13)$ for $V_{A}$ adjusted to give a nominal value of $V_{0}^{+}=10$ volts:

$$
\frac{\partial V_{0}^{+}}{\partial V_{A}}=\frac{\left(V_{0}^{+}+V_{D}\right)\left(\varepsilon^{x}-1\right)^{2}}{(a+1) \times \varepsilon^{x}\left(V_{B}+\phi_{4}-\phi_{3}\right)},
$$

with $x$ given by Eq. $(2-15)$. The Eq. $(2-19)$ shows that the smal1-signal low-frequency ga in decreases monotonically about $25 \%$ from $V_{B}=5 \mathrm{~V}$ to $V_{B}=14 \mathrm{~V}$. The value of the Eq. $(2-19)$ transfer function is in the range 0.6 to 0.82 .

Smal1-signal frequency response measurements for the switching regulator (output of the op amp to the $\mathrm{v}_{0}^{+}$terminal) show that a reasonable approximation for the normalized frequency response is

$$
H_{n s}=\frac{1}{\left(1+j \frac{f}{400}\right)^{2}} \text {, }
$$

which gives the expected $12 \mathrm{~dB} /$ octave slope due to the coil inductance and the filter capacitor (Fig. 2-1).

The system loop transmission, $T(f)$, is the product of the right- 
hand sides of Eqs. $(2-16),(2-19)$ and $(2-20)$, which for $k=1.5 \times 10^{5}$, $\partial V_{0}^{+} / \partial V_{A}=0.82$, and the components of $F i g .2-1$ is approximately

$$
T(f) \approx \frac{-5.0 \times 10^{4}}{\left(1+j \frac{f}{2.5 \times 10^{-3}}\right)\left(1+j \frac{f}{400}\right)^{2}} .
$$

The worst case occurs for the largest value of $\partial V_{0} / \partial V_{A}$ and 0.4 times the nominal value of $C_{f}\left(X 7 R\right.$ material). ${ }^{l}$ The zerc- $d B$ crossing frequency for $T(f)$ given by Eq. (2-21) is about $116 \mathrm{~Hz}$. The system phase margin is about $58^{\circ}$ which assures strong stability against oscillations. The very high low-frequency value of $T(f)$ causes the output voltage regulation to depend almost entirely on the zener reference diode. Both the high $T(0)$ and the large phase margin allows wide variation in component values while still maintaining proper operation of the converter.

\section{2-6 Other Design Considerations}

The parallel VMOS transistors used as the regulator switch were isolated with $25 \Omega$ parasitic suppressors installed in series with each gate. Ferrite beads are perhaps a better choice because of increased gate voltage risetime; however, the ferrite material in typical beads have Curle points below $230^{\circ} \mathrm{C}$.

The rectifier diodes used in the previous dc-dc converter ${ }^{1}$ were diode-connected 2N4861 JFET's which had negligible leakage current at $230^{\circ} \mathrm{C}$ but had appreciable "on" resistance. The converter of Fig. 2-7 uses the drain-substrate $p-n$ junction diode of an $n$-channel VMOS VN106iv2 transistor which has a lower forward voltage drop $(0.3 \mathrm{~V}$ compared to 0.55 for the $2 \mathrm{~N} 4861$ at $230^{\circ} \mathrm{C}$ ). The larger leakage current (about $200 \mu \mathrm{A}$ ) was acceptable at $230^{\circ} \mathrm{C}$. Use of the VMOS diodes resulted in 
higher regulator efficiency, and it is-expected that the regulator reliability will be improved since the VMOS devices have much larger geometry than the JFET's which were being operated near their maximum forward current limit. However, preliminary radiation effects studies indicate that the VMOS devices will probably be unacceptable for use in radiation environments because of changes induced in the gate threshold voltage. 


\subsection{EXPERIMENTAL RESULTS}

The $J C$ to $D C$ convertor shown in Fig, 2-1 was wired with discrete components and 10/90 (10\% tin, $90 \%$ lead) solder on a $4^{\prime \prime} \times 5^{\prime \prime}$ ceramic plate for high temperature testing.

All ceramic capacitors were chip capacitors (such as would be utilized in a hybrid thick-film circuit). The output filter capacitors were $10 \mu \mathrm{F}$ Phillips solid electrolytics, as was the $2 \mu \mathrm{F}$ capacitor on the simulated battery supply. All components except the load resistors were placed inside the test overn, including the $7.5 \mathrm{~V} 1 \mathrm{~W} 2971 \mathrm{~B}$ Zener connected to the $12.6 \mathrm{~V}$ supply through a $22 \Omega$ res istor to simulate the isotopic power supply. Leads were extended outside the oven to operate the circuit from either the zener or directly from a variable dc supply. The $2.2 \mu \mathrm{F}$ input capacitor was connected at the circuit board to be in place when the variable supply was used.

Measurements were made of the output voltages and ripple, zener voltage and input current, reference voltage and current, frequency, duty cycle, and power consumption. In addition the error amplifier output was monitored to see if it varied as predicted by the design theory, and other currents were measured to determine losses in various parts of the circuit. From the above data, overall efficiency was calculated as well as the efficiency of the switching regulator. This was done by determining the power loss of each of two parts of the circuit. The power $P_{E}$ was dissipated in the control electronics which consists of the multivibrator, and error amplifier circuit. All other losses were due to the switching regulator and were labeled $P_{R}$. These losses included core loss, winding loss, rectifier voltage drop and leakage current loss, VMOS "on" resistance loss and the leakage current and capacitor losses. The power $P_{E}$ was calculated from the data recorded 
and subtracted from the input power to determine $P_{R}$. From this result, the regulator efficiency could be defined as the total converted power divided by the power into the regulator.

After some failures of certain types of metal film resistors and an epoxy packaged transistor, which was replaced with the DI3424 in a metal package, the circuit operated properly at $230^{\circ} \mathrm{C}$. The test was terminated after 240 hours. Measurements were taken with the zener supply to determine typical operating points and with the variable supply to determine the input range and variations with $V_{B}$.

\section{3-1 Operation with the Simulated I sotopic Supply}

Table 2.2 shows data taken on the DC-DC Converter II with the circuit connected to the simulated isotopic supply. This mode of operation is indicated by the $V_{B}=V_{Z}$ lines sketched on all following figures showing the experimental results. From Table 2.2 the supply (zener) voltage increases from $7.5 \mathrm{~V}$ at $25^{\circ} \mathrm{C}$ to $8.25 \mathrm{~V}$ at $230^{\circ} \mathrm{C}$; this change is the cause of most of the variations with temperature. Frequency regulation (Fig. 2-4) is reasonable, $71.5 \mathrm{kHz}$ at $25^{\circ} \mathrm{C}$ to $83.3 \mathrm{kHz}$ at $230^{\circ} \mathrm{C}$, but indicates that temperature dependent effects, such as charge removal on the timing capacitors, have more effect than reduced duty cycle at $230^{\circ} \mathrm{C}$ which tends to reduce the frequency.

Output voltage changes with temperature were less than would be expected from looking at the reference voltage which increased by $80 \mathrm{mV}$ with temperature. Other second order effects such as error amplifier input bias current must have compensated for the increased reference voltage. For other components however, a different temperature coefficient can be expected but should still be reasonable. 


\begin{tabular}{|c|c|c|c|c|c|}
\hline $\begin{array}{l}\text { MEASURED QUANTITY } \\
V_{0}=V_{E}, I_{0}^{+}=I_{0}^{-}=15 \mathrm{~mA} \text { UNLESS } \\
\text { NOTED. }\end{array}$ & $25^{\circ} \mathrm{C}$ & $75^{\circ} \mathrm{C}$ & $125^{\circ} \mathrm{C}$ & $175^{\circ} \mathrm{C}$ & $230^{\circ} \mathrm{C}$ \\
\hline $\begin{array}{l}V_{Z} \text { IV) } \\
\text { LOADED ZENER VOLTAGE }\end{array}$ & 7.495 & 7.651 & 7.850 & 8.042 & 8.242 \\
\hline $\begin{array}{l}I_{Z}(m A) \\
\text { LOADED ZENER CURRENT }\end{array}$ & 152 & 145 & 137 & 128 & 114 \\
\hline $\begin{array}{l}\text { IO }(m A) \\
\text { CONVERTER INPUT CURRE }\end{array}$ & 66.4 & 66.8 & 66.0 & 67.0 & 72.0 \\
\hline \begin{tabular}{lc|}
$V_{0}^{*}(V)$ & POSITIVE \\
REGULATE D OUTPUT VOLTAGE \\
\end{tabular} & 0.120 & 10.126 & 10.042 & 10.114 & 10.115 \\
\hline $\begin{array}{lr}V_{0}^{-}(V) & \text { NEGATIVE } \\
\text { TRACKING OUTPUT VOLTAGE } \\
\end{array}$ & 10.117 & 10.128 & 10.048 & 10.154 & 10.132 \\
\hline $\begin{array}{l}V_{A}(V) \text { ERROR AMPLIFIER } \\
\text { OUTPUT VOLTAGE }\end{array}$ & 1.80 & 1.59 & 1.30 & 0.93 & 0.56 \\
\hline $\begin{array}{l}f(K H E) \text { FREQUENCY OF } \\
\text { OPERATION }\end{array}$ & 71.53 & 74.45 & 77.00 & 80.44 & 83.28 \\
\hline $\begin{array}{l}\eta(\%) \text { TOTAL EFFICIENCY } \\
\text { OF DC.DC CONVERTER II }\end{array}$ & 61.0 & 59.4 & 58.2 & 56.5 & 51.2 \\
\hline $\begin{array}{l}\eta_{R}(\%) \text { EFFICI } \\
\text { SWITCHING RE }\end{array}$ & 83.6 & 84.0 & 85.5 & 86.6 & 86.6 \\
\hline $\begin{array}{l}\text { D DUTY CYCLE MEASURED } \\
\text { AT VMOS DRAIN }\end{array}$ & .597 & 505 & .585 & .582 & .574 \\
\hline $\begin{array}{l}\text { FUNDAMENTAL RIPPLE } \\
V_{0}^{+} / V_{0}^{-},(\mathrm{mV} / \mathrm{mV})\end{array}$ & $46 / 42$ & $36 / 28$ & $26 / 22$ & $20 / 18$ & $16 / 13$ \\
\hline $\begin{array}{lc}V_{W} \text { (V) } & \text { DI3424 } \\
\text { REFERENCE VOLTAGE }\end{array}$ & 6.921 & 6.937 & 6.957 & 6.980 & 7.003 \\
\hline $\begin{array}{lc}\text { Ir }(m A) & \text { DI3424 } \\
\text { REFERENCE CURRENT }\end{array}$ & .016 & .515 & .501 & .523 & .519 \\
\hline $\begin{array}{l}\text { PE/\% TOTAL LOSS }(\mathrm{mW} / \%) \\
\text { LOSS IN M.V. AND AMPLIFIER }\end{array}$ & $126 / 65$ & $141 / 68$ & $158 / 73$ & $180 / 77$ & $235 / 81$ \\
\hline $\begin{array}{l}\text { PR/\% TOTAL LOSS }(m W / \%) \\
\text { LOSS IN SWITCHING REG. }\end{array}$ & $68 / 35$ & $67 / 32$ & $59 / 27$ & $54 / 23$ & $54 / 19$ \\
\hline $\begin{array}{l}\text { LOAD REGULATION-V } V_{0}^{+}(90 \text { of } 10 \mathrm{~V}) \\
4 \mathrm{~mA} \leq I_{0}^{+}, I_{0}^{-} \leq 16 \mathrm{~mA}\end{array}$ & 0.11 & & 0.13 & 0.18 & 0.21 \\
\hline $\begin{array}{l}\text { LOAD REGULAT1ON-V-(\%o of } 10 \mathrm{~V}) \\
4 \mathrm{~mA} \leq I_{0}^{+}, I_{0} \leq 16 \mathrm{~mA}\end{array}$ & 1.94 & & 1.94 & 2.46 & 2.69 \\
\hline $\begin{array}{l}\text { MINIMUM INPUT VOLTAGE } \\
\text { (V) } 15 \mathrm{~mA} \text { LOAD }\end{array}$ & 4.0 & & 5.0 & 5.0 & 5.5 \\
\hline $\begin{array}{l}\text { MAXIMUM INPUT VO } \\
(V) \quad 15 \mathrm{~mA} \text { LOAD }\end{array}$ & 16 & & 15.0 & 15.0 & 14. \\
\hline
\end{tabular}

Table 2.2

Measured typical operating points and performance specifications of DC to DC Converter II with simulated isotopic supply. 


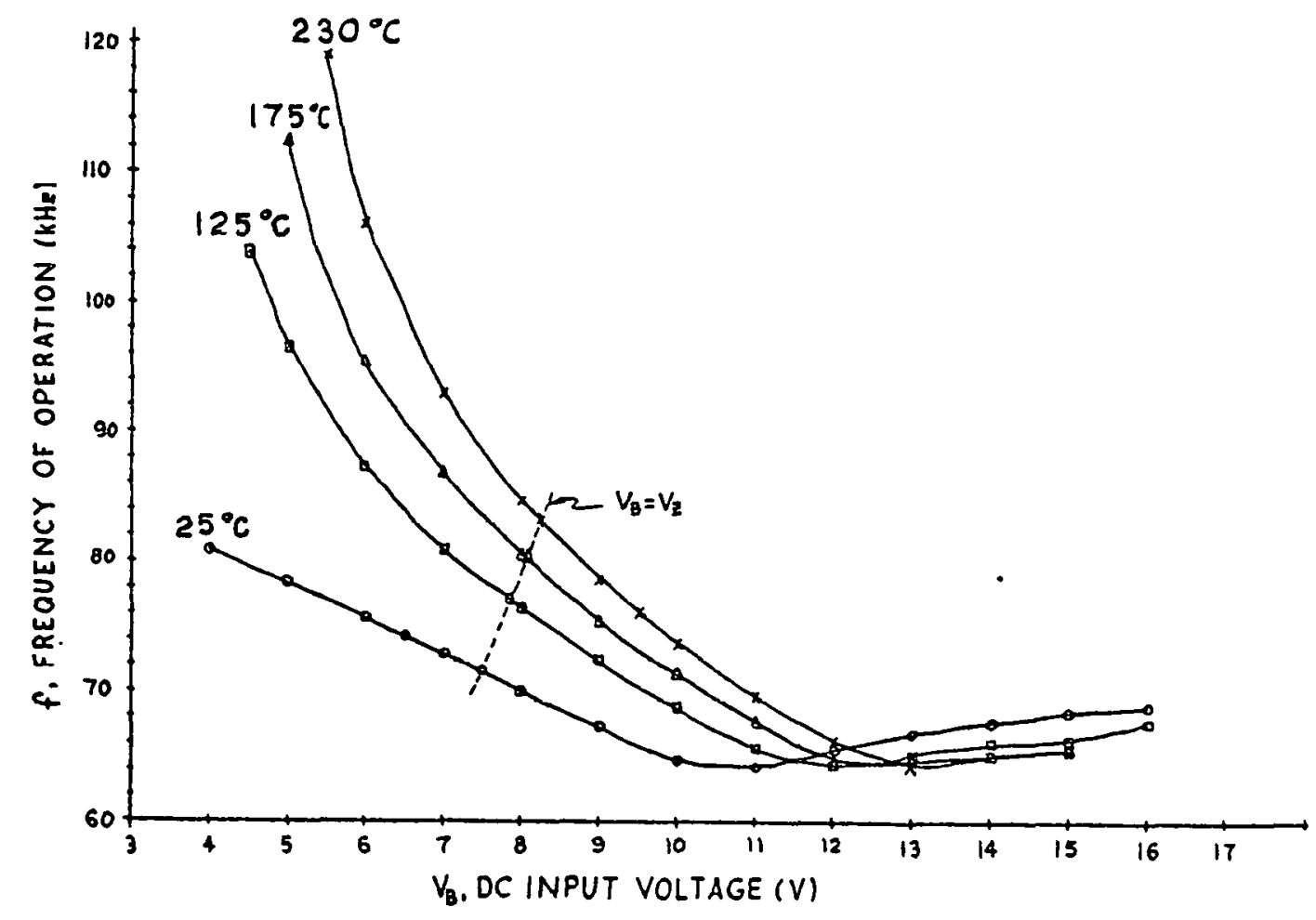

Fig. 2-4. Frequency of Multivibrator as a Function of Battery Voltage and Temperature. 
The efficiency, though not of great importance for our application due to the small output power, does indicate something about the temperature performance of the circuit. From a temperature of $25^{\circ} \mathrm{C}$ to $230^{\circ} \mathrm{C}$, overall efficiency (Fig. 2-5) decreases from $61 \%$ to $51.2 \%$ but the efficiency of the switching regulator increases with temperature. This indicates that multivibrator power consumption is increasing rapidly with temperature. This is perhaps better seen in the $P_{R}$ and $P_{E}$ calculations upon which the efficiencies are based. These results are plotted in Fig. 2-6, and the efficiencies $n$ and $n_{R}$ in Figs. 2-5 and $2-7$, respectively. In Fig. $2-8$ note also that $V_{A}$ was $1.8 \mathrm{~V}$ at $25^{\circ} \mathrm{C}$ and 0.56 at $230^{\circ} \mathrm{C}$, well away from the saturation levels. Even with component tolerances and a different nominal zeher voltage, the error amplifier should be well within its linear range.

Load regulation with an unsymmetrical load was examined by setting the output currents from $0-20 \mathrm{~mA}$ in $4 \mathrm{~mA}$ sters. A11 possible comb inations of $\mathrm{I}_{0}^{+}$and $\mathrm{I}_{0}^{-}$were tested. The results are indicated in Table 2.2. It was found that maximum $\mathrm{V}_{0}^{+}$and $\mathrm{V}_{0}^{-}$occurred for maximum $\mathrm{I}_{0}^{+}$and minimum $\mathrm{I}_{0}^{-}$. Minimum $\mathrm{V}_{0}^{+}$and $\mathrm{V}_{0}^{-}$occurred for minimum $\mathrm{I}_{0}^{+}$and maximum $I_{0}^{-}$. The positive voltage regulation is seen to be $0.21 \%$ of $10 \mathrm{~V}$ at worst case compared to $2.69 \%$ for the negative voltage. Strong voltage regulation was not considered critical and was 1 imited for the unregulated negative voltage by the equivalent series resistance of the regulator, hence no further effort was made to improve voltage regulation, From these experimental results it was also observed that load currents of $4 \mathrm{~mA}$ or more in either output was sufficient to bias the converter in the proper mode of operation. That is, this current was enough to 


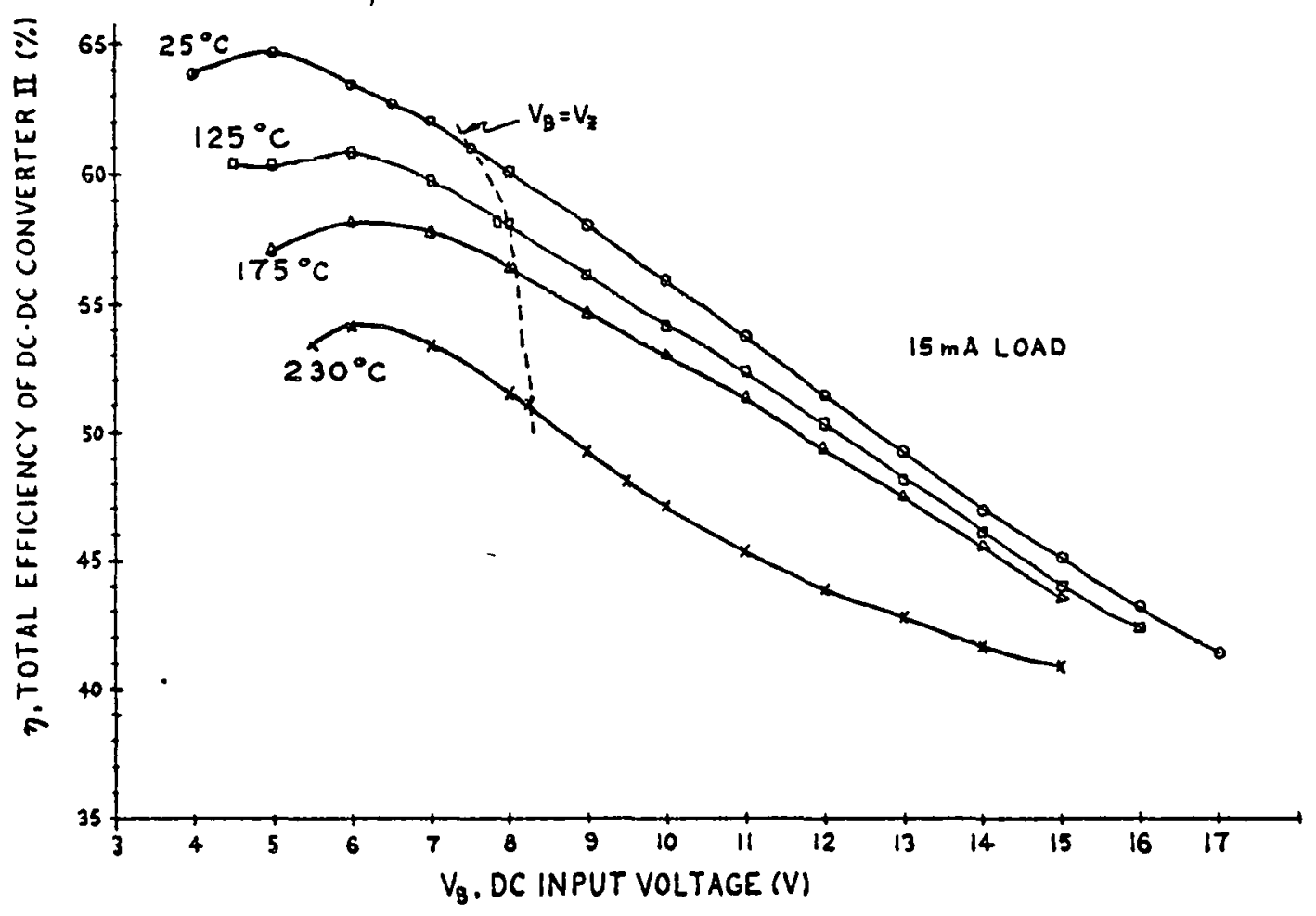

Fig. 2-5. Total Efficiency of the $D C$ to $D C$ Converter as a Function of Battery Voltage and Temperature. 


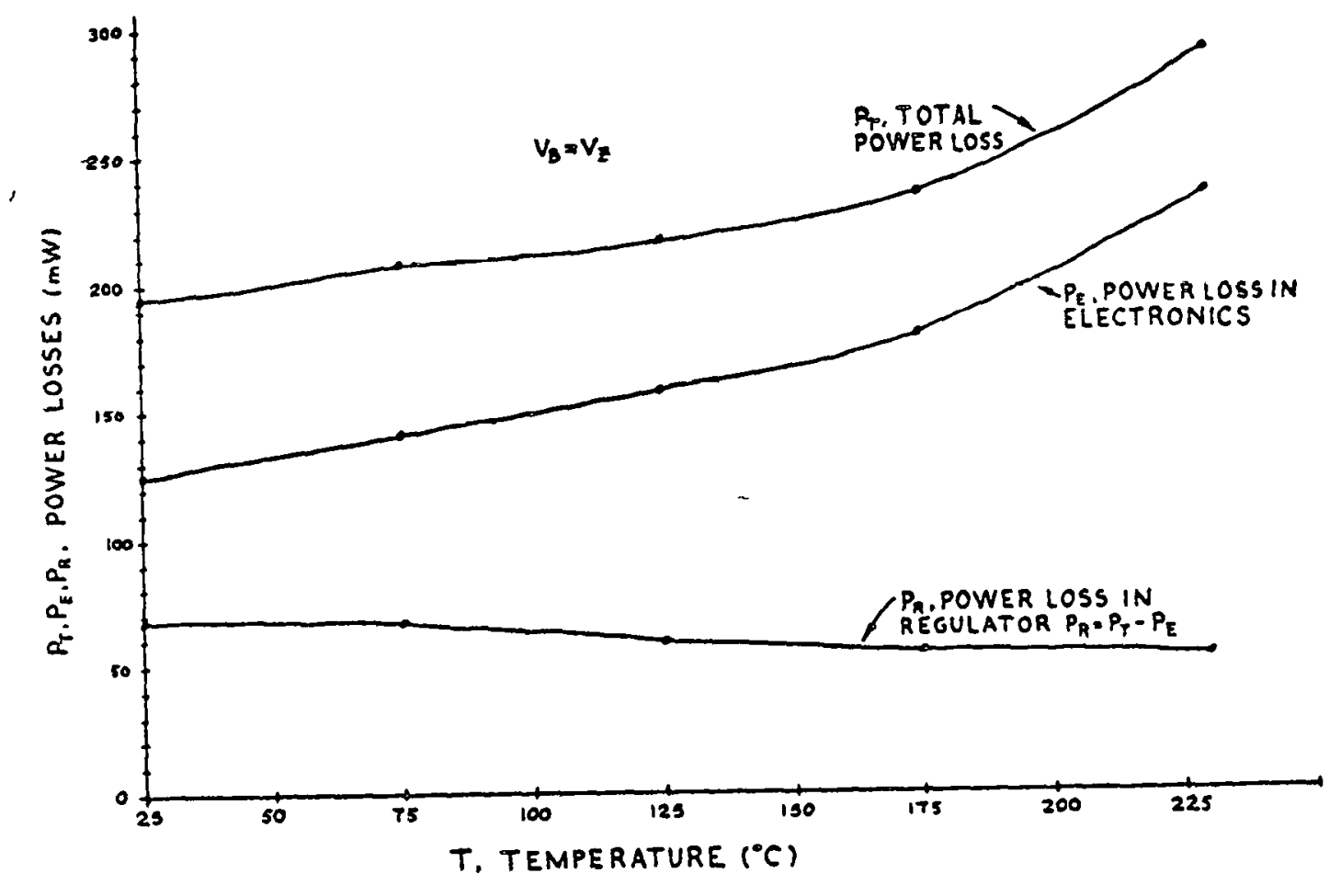

Fig. 2-6. Power losses as a Function of Temperature. $P_{T}=$ total loss; $P_{E}=$ power consumed by electronics; $P_{R}=$ power consumed in switching. regulator; $P_{T} \stackrel{R}{=} P_{R}+P_{E}$. 


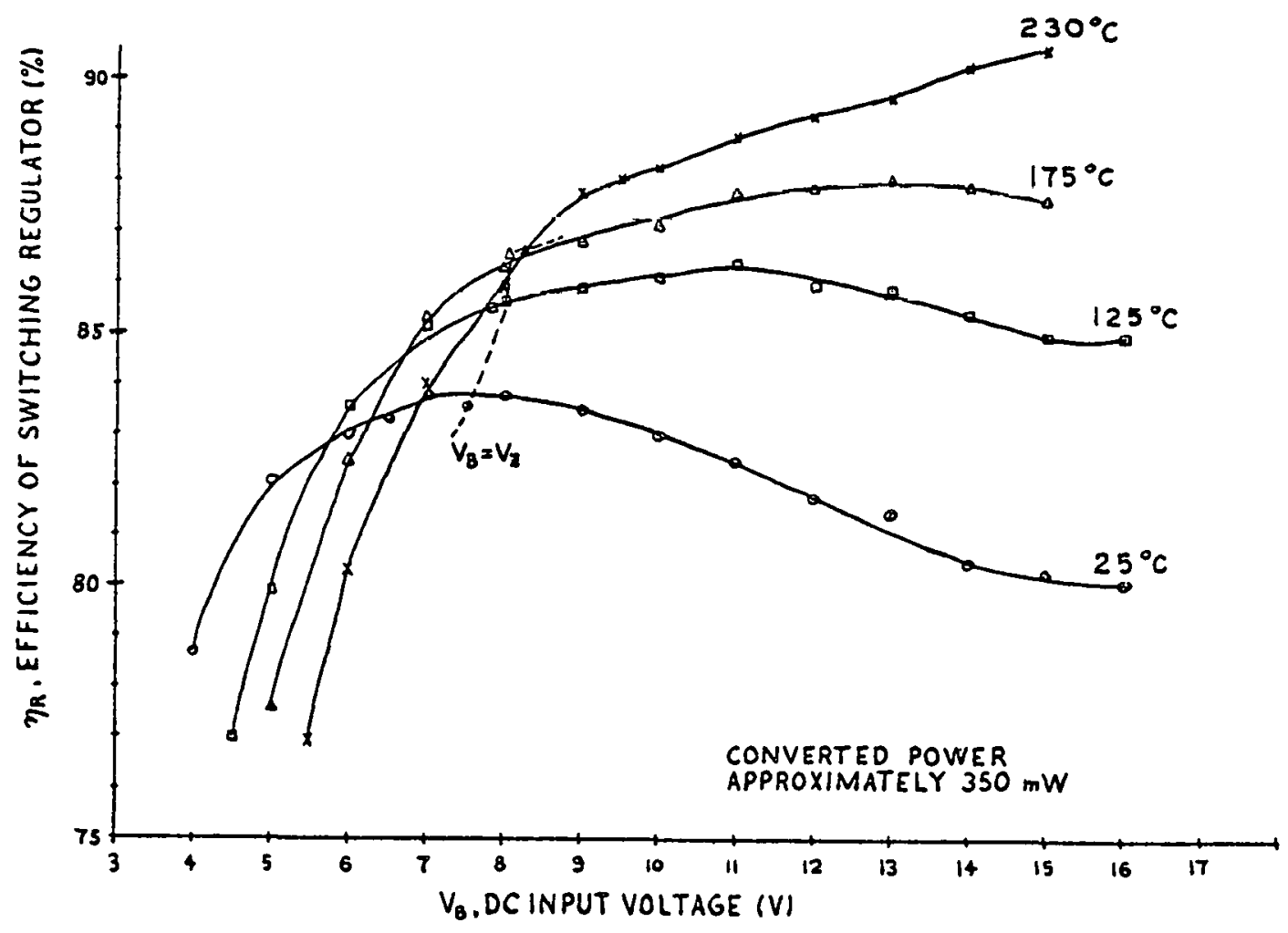

Fiy. 2-7. Efficiency of the Switching Regulator as a Function of Battery Voltage and Temperature. (Total output power divided by the power into the VMOS switch). 


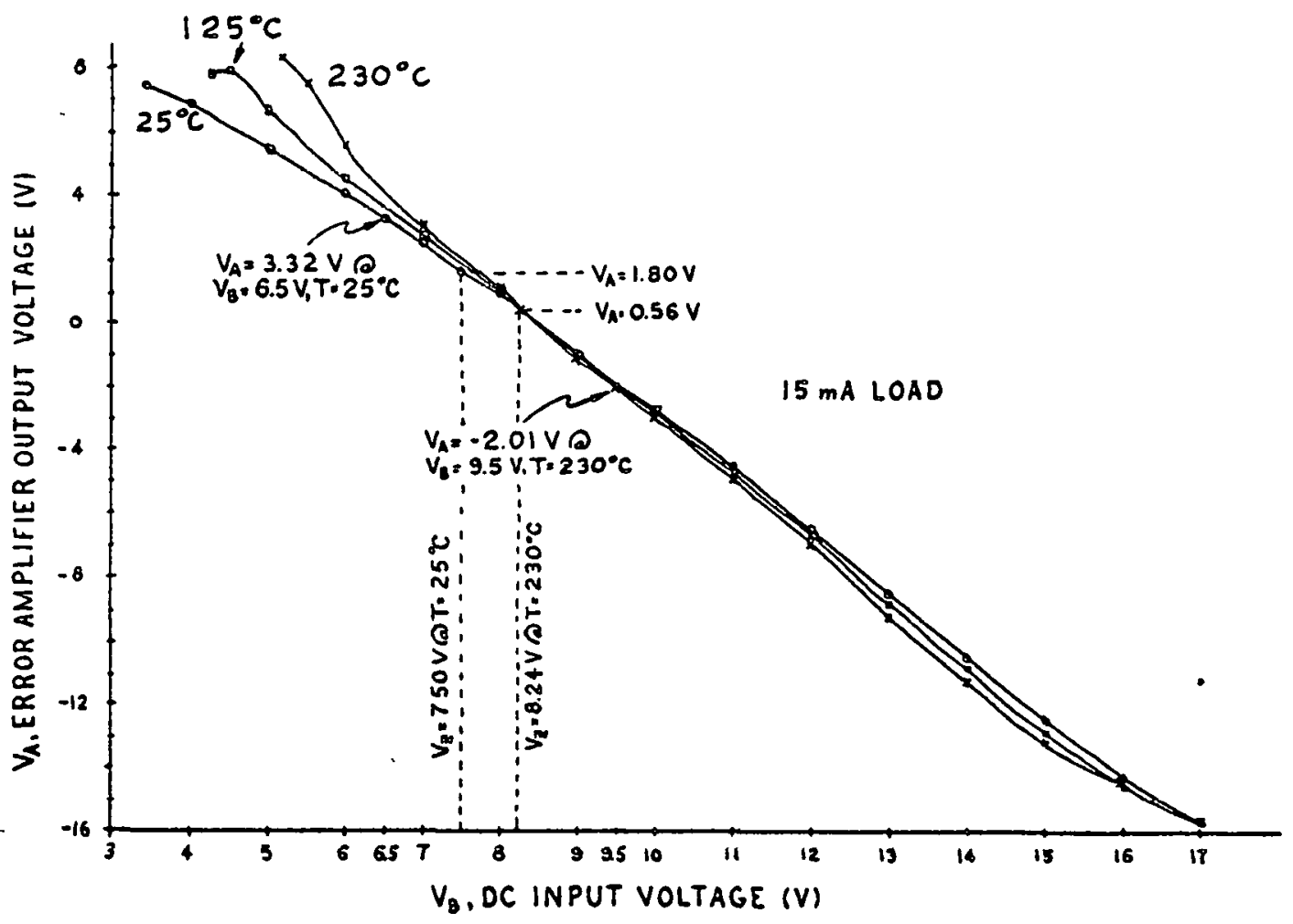

Fig. 2-8. Error Amplifier Output Voltage as a Function of Battery Voltage and Temperature (10V nominal output). 
prevent the inductor current from going to zero during part of the switching cycle.

\section{3-2 Operation with a Variable Input Supply Voltage}

Fig. 2-9 shows the regulated positive output voltage as a function of the input supply voltage (battery) $V_{B}$. The input dynamic range can be determined from this plot to extend from 5.5 to $14 \mathrm{~V}$ worst case at $230^{\circ} \mathrm{C}$. Correlating the limits of regulation on Fig. 2-9 with the error amplifier output voltage of Fig. 2-3 shows that the input voltage range is determined by saturation of the error amplifier which can be easily adjusted, if necessary, in later circuit designs. Fig. 2-8 shows also that the theoretical values for $V_{A}$ were close to the experimental values.

The frequency decreases as expected (Fig. 2-4) with $V_{B}$ for costant temperature, and increases with temperature for constant $V_{B}$. This is not true at higher values of $V_{B}$ where most likely the base-emitter junctions of the multivibrator transistors are going into reverse breakdown and consequently limiting the initial timing capacitor voltages. For the isotopic supply case where $V_{B}=V_{Z}$, the Zener diode voltage, $V_{Z}$ does not increase enough with temperature to cancel temperature effects so there is a $16 \%$ increase in frequency at $230^{\circ} \mathrm{C}$.

Total efficiency (Fig. 2-5) is a maximum at smaller values of $V_{B}$ where multivibrator losses would be less. At every value of $V_{B}$, efficiency decreases with temperature. This is not the case for regulator efficiency shown in Fig. 2-7 where below about $7 \mathrm{~V}$ this efficiency decreases with temperature and above $7 \mathrm{~V}$ increases with temperature. The VMOS transistor losses probably dominate at lower $V_{B}$ due to the 


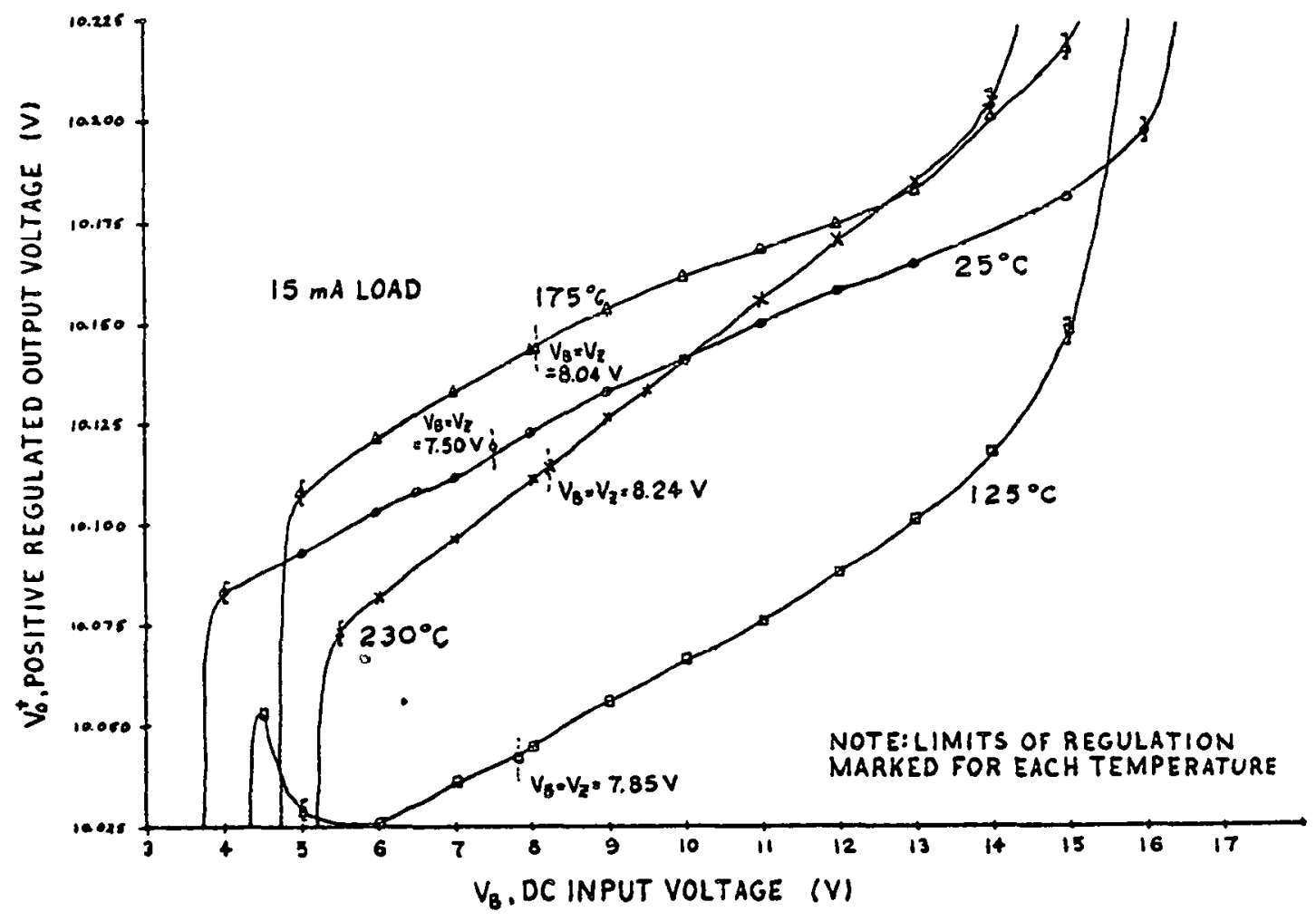

Fig. 2-9. Positive Regulated Output Voltage as a Function of Battery Voitage and Temperature. 
high current; these losses would likely increase with temperature. Rectifier voltage drop probably dominates at high $V_{B}$ and decreases with temperature with the VN106N2 transistors connected as diodes.

Figure 2-6 shows the power losses, $P_{T}, P_{E}, P_{R}$ at $V_{B}=V_{Z}$ and clearly indicate that the electronics power losses are dominant at high temperatures.

The battery current $I_{B}$ is shown as a function of $V_{B}$ in Fig. 2-10, and duty cycle as a function of $V_{B}$ at $25^{\circ} \mathrm{C}$ and $230^{\circ} \mathrm{C}$ is shown in Fig. $2-11$. Note that this is consistent with regulator efficiency in that duty cycle increases with $T$ below about $7 \mathrm{~V}$ and-decreases with $T$ above $7 \mathrm{~V}$.

\section{3-3 Converter Start-Up}

Each time a set of measurements was taken, the supply was turned on and off and abruptly disconnected several times to see if the circuit would start-up. This is by no means a conclusive test for start-up but a failure to start is significant.

First, it was found that the circuit would start even if the battery supply was 1 imited to currents as low as $140 \mathrm{~mA}$. This is because of the relatively tight duty cycle limits as compared to converter I which would draw roughly $300 \mathrm{~mA}$ initially.

Secondly, it was possible to cause the multivibrator to latch in a stable static mode at $230^{\circ} \mathrm{C}$ by turning the supply on and off in just the right way. When left alone,as it cooled it would start again at about $200^{\circ} \mathrm{C}$ and was not seen to latch at any temperature other than $230^{\circ} \mathrm{C}$. Investigation of this phenomenon revealed that latchup occured with $Q_{2}$ saturated and $Q_{1}$ biased active through the diode start-up network. The start-up network prevented $Q_{1}$ and $Q_{2}$ from both saturating 


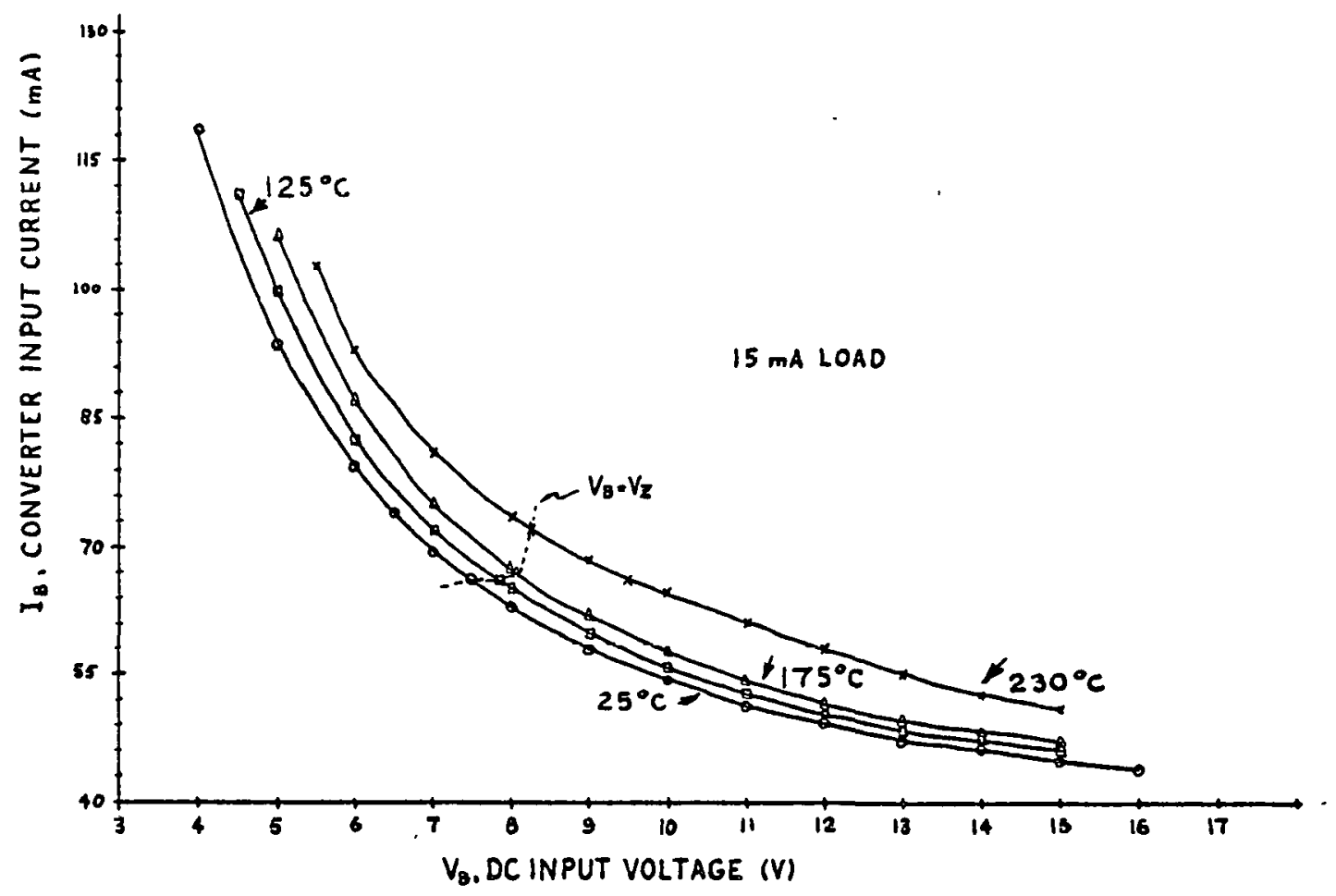

Fig. 2-10. Battery Current as a Function of Battery Voltage and Temperature. 


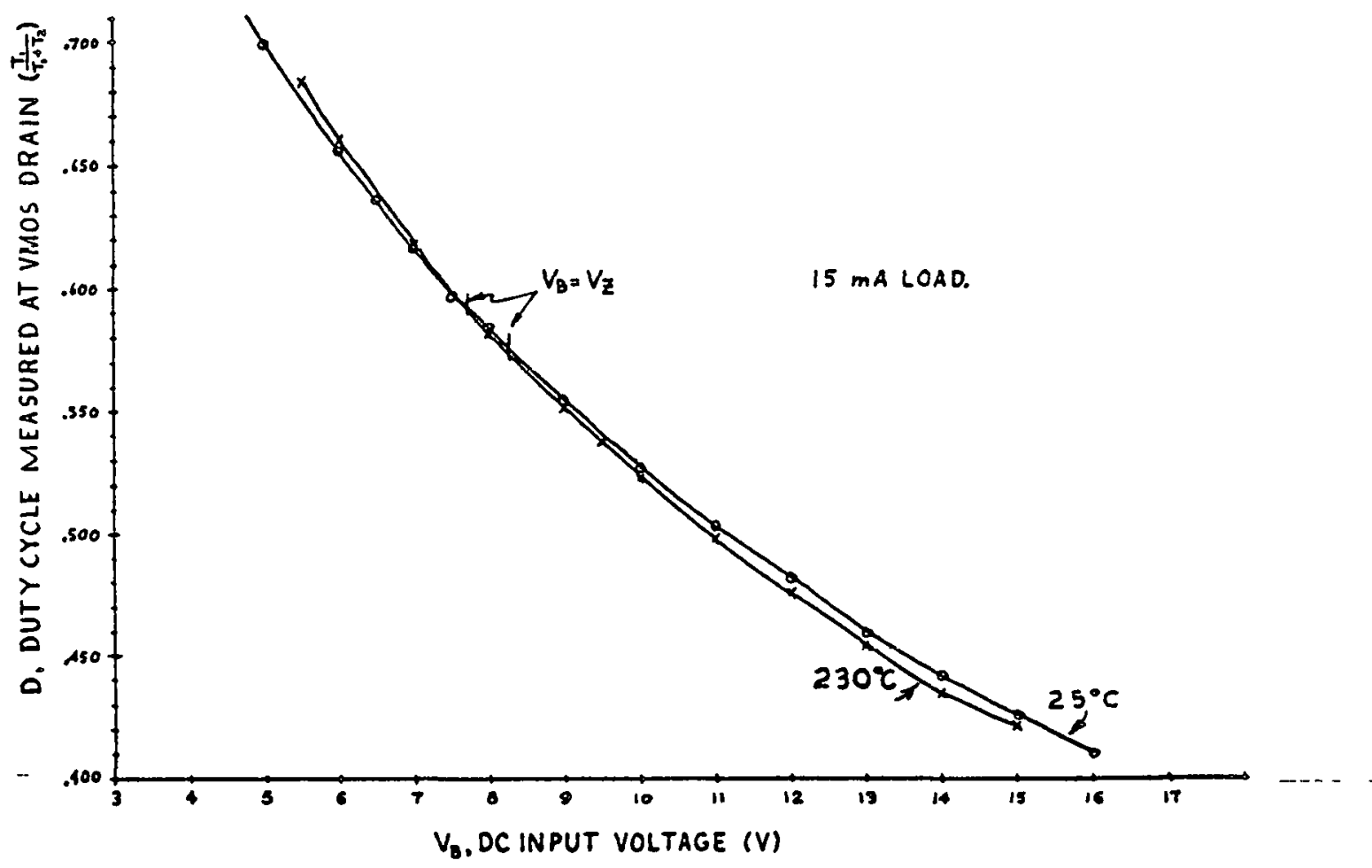

Fig. 2-11. Duty Cycle as a Function of Battery Voltage for $\mathrm{T}=25^{\circ} \mathrm{C}$ and $\mathrm{T}=230^{\circ} \mathrm{C}$. 
but allowed $Q_{1}$ to be active in a negative-feedback loop which provided stability. This is a mode possible in all other versions of the multivibrator used and requires further investigation. For maximum reliability it is required to show that no static stable modes of operation can exist. This may be possible by an analysis of the loop gain in the multivibrator after adjustment of component values or more drastic modifications. The latch-up problem is avoided if sufficient time is allowed for the charge on all capacitors to dissipate before turning the converter back on. 
CHAPTER 3

AMPLIFIER - DISCRIMINATOR CIRCUITS FOR $230^{\circ} \mathrm{C}$ OPERATION

\subsection{INTRODUCTION}

With the reduction of system operating temperature from the $250^{\circ} \mathrm{C}$ $300^{\circ} \mathrm{C}$ environment of the previous years contract work to a $200^{\circ} \mathrm{C}-230^{\circ} \mathrm{C}$ range, several additional circuit designs became worthy of investigation. These were concerned with utilizing available monolithic dielectricisolated operational amplifiers, with a goal of reducing the number of wire bonds or interconnects and also lowering the required operating current required from the $d c-d c$ converter. There are two different designs that were evaluated.

\subsection{OP-AMP CIRCUIT II}

This circuit is identical to that in current use by ORNL (the ORNL circuit is hereafter referred to as Op Amp Circuit I), which utilizes four HA2625 op amp chips on a 2 inch $\times 2$ inch thick-film substrate, except that Circuit II accomplishes the entire design with one IC chip, the HA4625 quad op amp. The schematic diagram for Circuit II is shown in Fig. 3-1, where amplifiers 1 and 2 comprise signal amplification, amplifier 3 is an RC-CR filter with a $2 \mu \mathrm{sec}$ time constant, and amplifier 4 is the discriminator-monostable multivibrator pulse shaper. The thick-film layout of this circuit is in Fig. 3-2; the entire circuit was constructed on a 1 inch $\times 1$ inch ceramic substrate for evaluation.

\section{2-1 Circuit II Characteristics}

The use of the quad HA4625 op amp gave a reduced current drain when compared with op Amp Circuit I, of 2.8 ॥A versus $10 \mathrm{~mA}$, at $25^{\circ} \mathrm{C}$. 

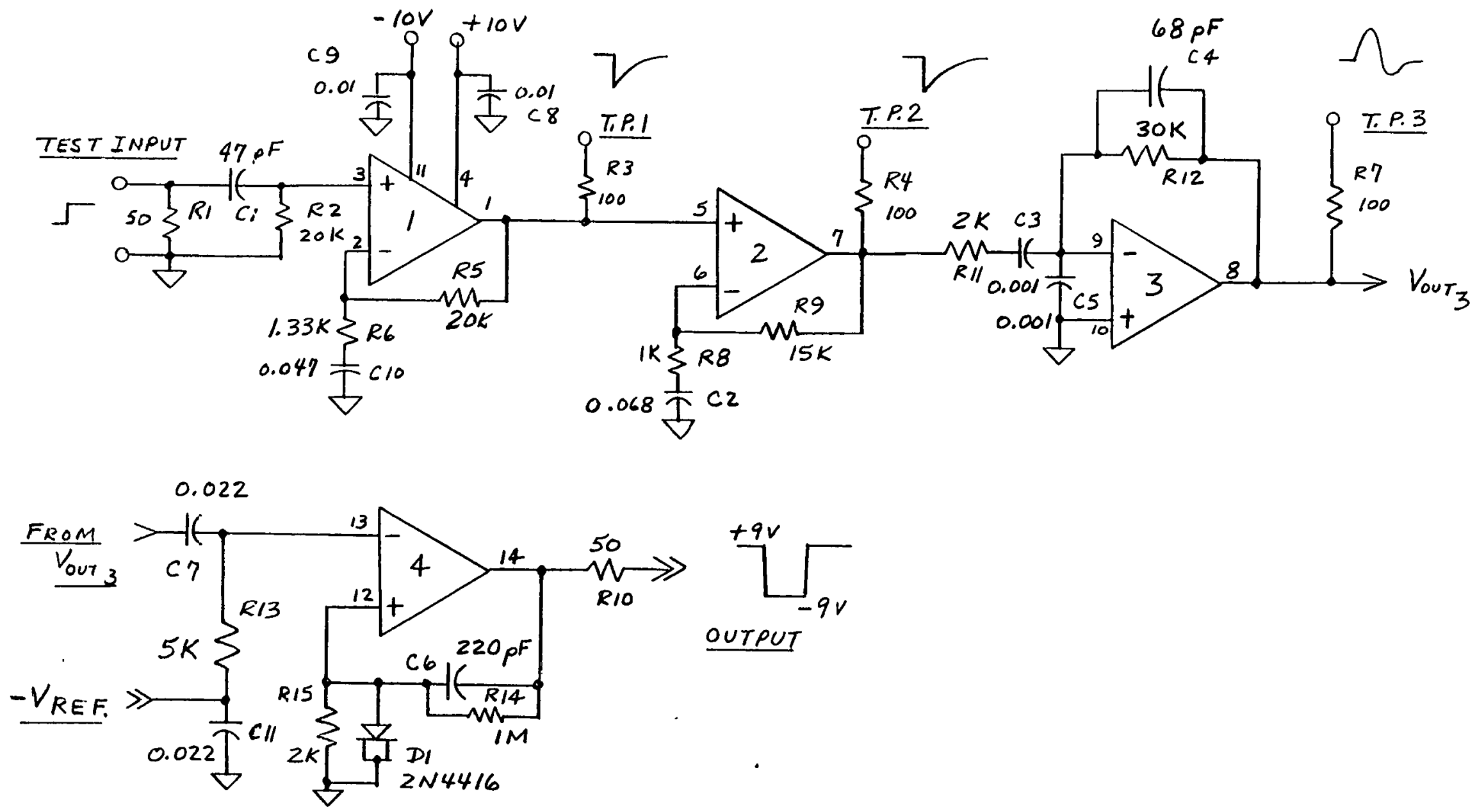

\section{NOTES:}

1. ALL RESISTORS IN OHMS; ALL CAPACITORS IN MICROFARADS, UNLESS OTIHERWISE STATED.

2. AMPLIFIER IS HAH625, QUAD OP AMP

Figure 3-1. Schematic diagram of op-amp Circuit II . 


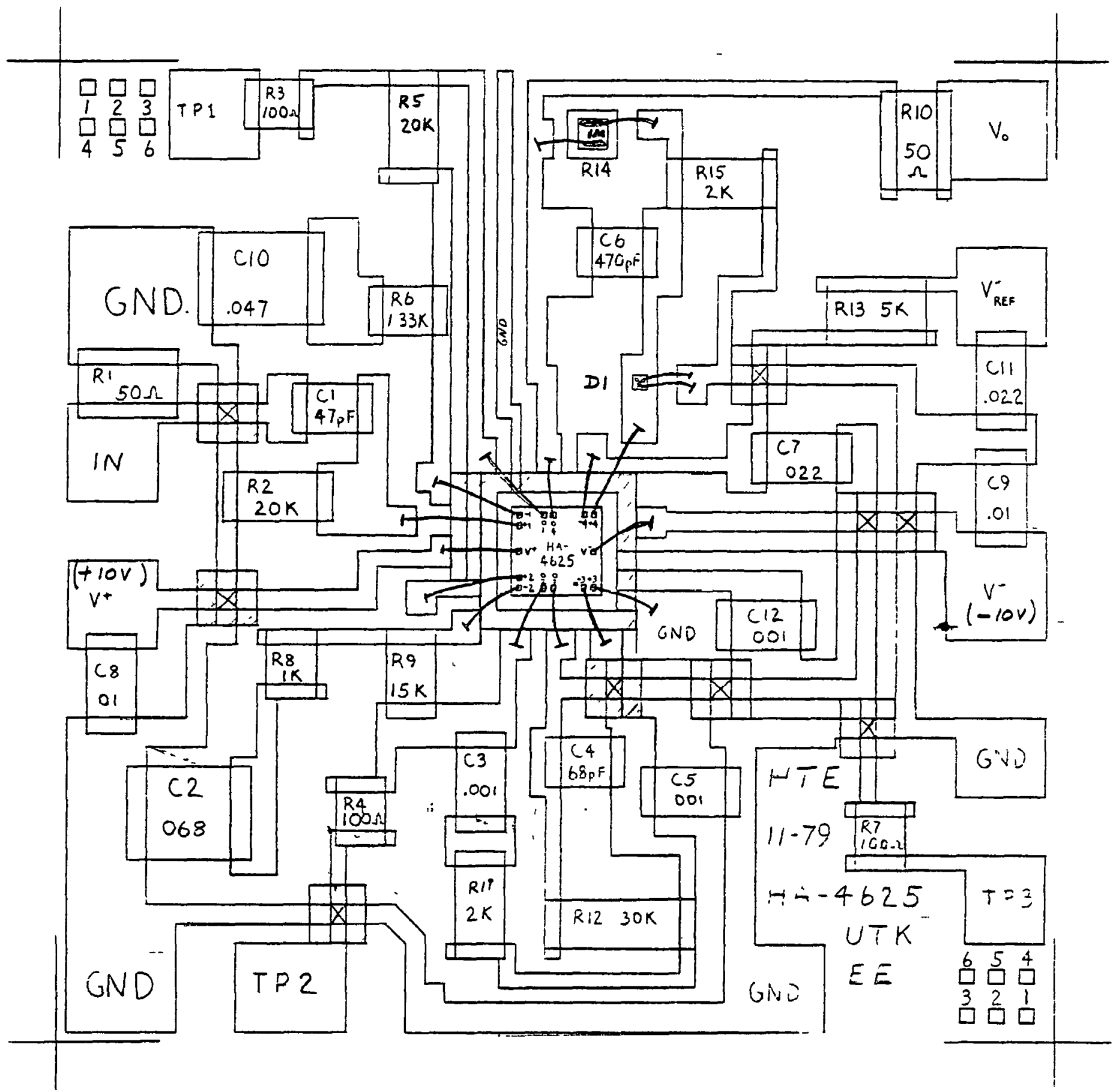

Figure 3-2, Thick-film layout of the quad op-amp

Circuit II. Overall substrate size is 1 in $\times 1$ in. 
Most significant, however, was the fact that the number of wire bonds was reduced from 30 for Circuit I to 18 for Circuit II.

Basic problems developed when the operating temperature was increased. The HA4625 has a $70 \mathrm{MHz}$ gain-bandwidth product, but is uncompensated for closed-10op gains < 10. Also, a11 4 op amps are biased from the same power supply lines, thus there is no way to have powersupply de-coupling as is present in the Circuit I design. These problems are apparent even at $25^{\circ} \mathrm{C}$, as is evident in the signal photographs of Fig. 3-3, where it is clearly apparent that the discriminator output signal is feeding back along the power lines and producing severe distortion of the output of amplifier 3. The circuit test board with the thick-film Circuit II is also indicated in Fig. 3-3. The DuPont hightemperature circuit board was employed for the test board.

At approximately $200^{\circ} \mathrm{C}$ the output signal of amplifier 3 started an oscillation at a frequency of $3.5 \mathrm{MHz}$. It was also apparent that some peculiar positive saturation limits were beginning to occur above $200^{\circ} \mathrm{C}$. At $230^{\circ} \mathrm{C}$ the total power supply current had increased from an initial room temperature value of $2.8 \mathrm{~mA}$ to $6 \mathrm{~mA}$.

Since there was no way to add effective frequency compensation or add power supply de-coupling, the decision was made to abandon this design. Later information on radiation effects on the HA4625 also confirmed the conclusion that this amplifier array is not suitable for further developmental design.

\subsection{OP-AMP CIRCUIT III}

The objectives of this design were to reduce the current drain of Circuit I, reduce the number of op amp chips (and therefore wire bonds) 


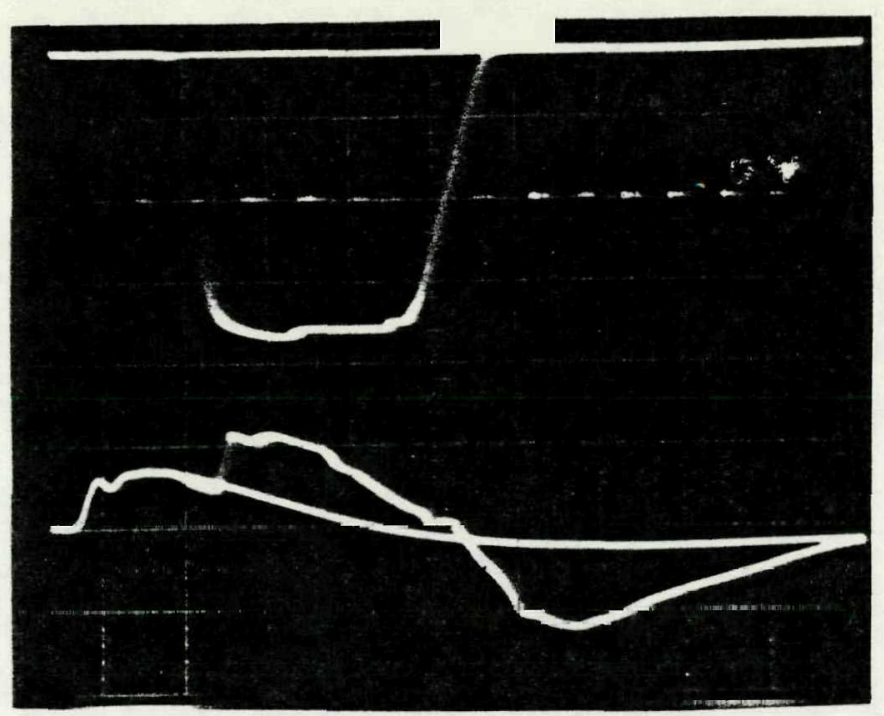

(a) Output of amplifier 3 (T.P.3), 2V/div. Upper trace is output of amplifier $4,5 \mathrm{~V} / \mathrm{div}$. Time is $1 \mu \mathrm{sec} / \mathrm{div}$.

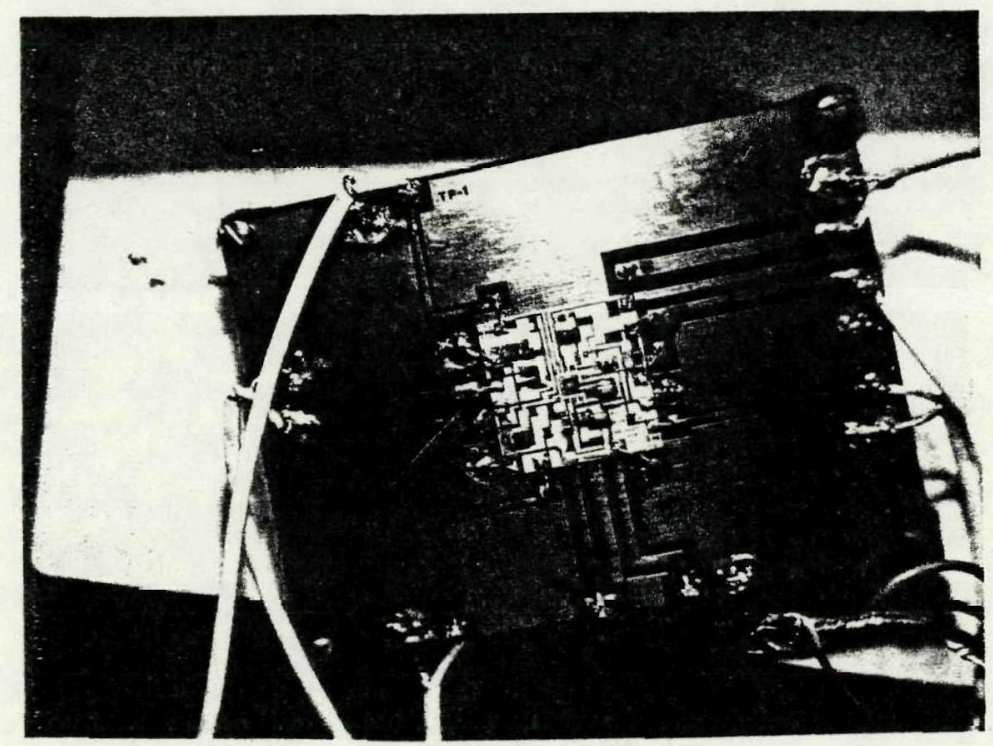

(b) Circuit test board with thick-film substrate.

Figure 3-3. Signal response characteristics of Circuit II. 
required, improve the discriminator - multivibrator temperature stability and allow a pulse-width reduction to $1 \mu \mathrm{sec}$, and also add a high current driver circuit that could directly drive the large gate capacitance of the VMOS crystal circuit.

The circuit diagram for Circuit III is shown in Fig. 3-4. The circuit was constructed as a hybrid thick-film IC on a $1 \frac{1}{4}$ inch $\times 1 \frac{1}{4}$ inch substrate, comprising amplifiers $A 1, A 2$, and $A 3$, along with the Q1-Q2 driver circuit. In Fig. 3-4 capacitors $\mathrm{C9}$ and $\mathrm{C13}$ are chosen for the appropriate output pulse width. Capacitor $C 4$ is not normally present, unless a filter response with a double-RC integration is required. Capacitors $\mathrm{C5}$ and $\mathrm{C7}$ are chosen for the required $\mathrm{RC}-\mathrm{CR}$ filter time constant. The amplifiers A1, A2, and A3 are HA2625 op amp units, the same as are employed in Circuit I. Diode $D I$ is a quad dielectricallyisolated array from Dionics, Inc.

\section{3-1 Circuit III Design Details}

In Fig. 3-4 amplifier Al has a design gain of +44 with a bandwidth of $2 \mathrm{MHz}$. Amplifier A2 has a pulse-gain of approximately -17 , and an RC-CR filter time constant of R6C.5 equal to. $.7 C 7$. For the circuit constructed, $\mathrm{C} 5$ was $1 \mathrm{nF}$ and $\mathrm{C} 7$ was $22 \mathrm{pF}$, for a time constant of 1.1 $1.2 \mu \mathrm{sec}$. It was also necessary in the A2 amplifier to provide a good high frequency ground for the substrate.

The discriminator circuit of $A 3$ is quite different from the design of Op Amp Circuit I. The discriminator trigger level is set by $V_{\text {out }}, R 13, R 14, R 10$ and diode $D 1$. Under quiescent conditions, $V_{\text {out }} \approx+6.2$ volts. The voltage at the inverting input of $A 3$ is $V_{D I B} \approx+0.6$ volts $\left(25^{\circ} \mathrm{C}\right.$ ), and at the non-inverting input of $A 3$ (Node 3 ) 

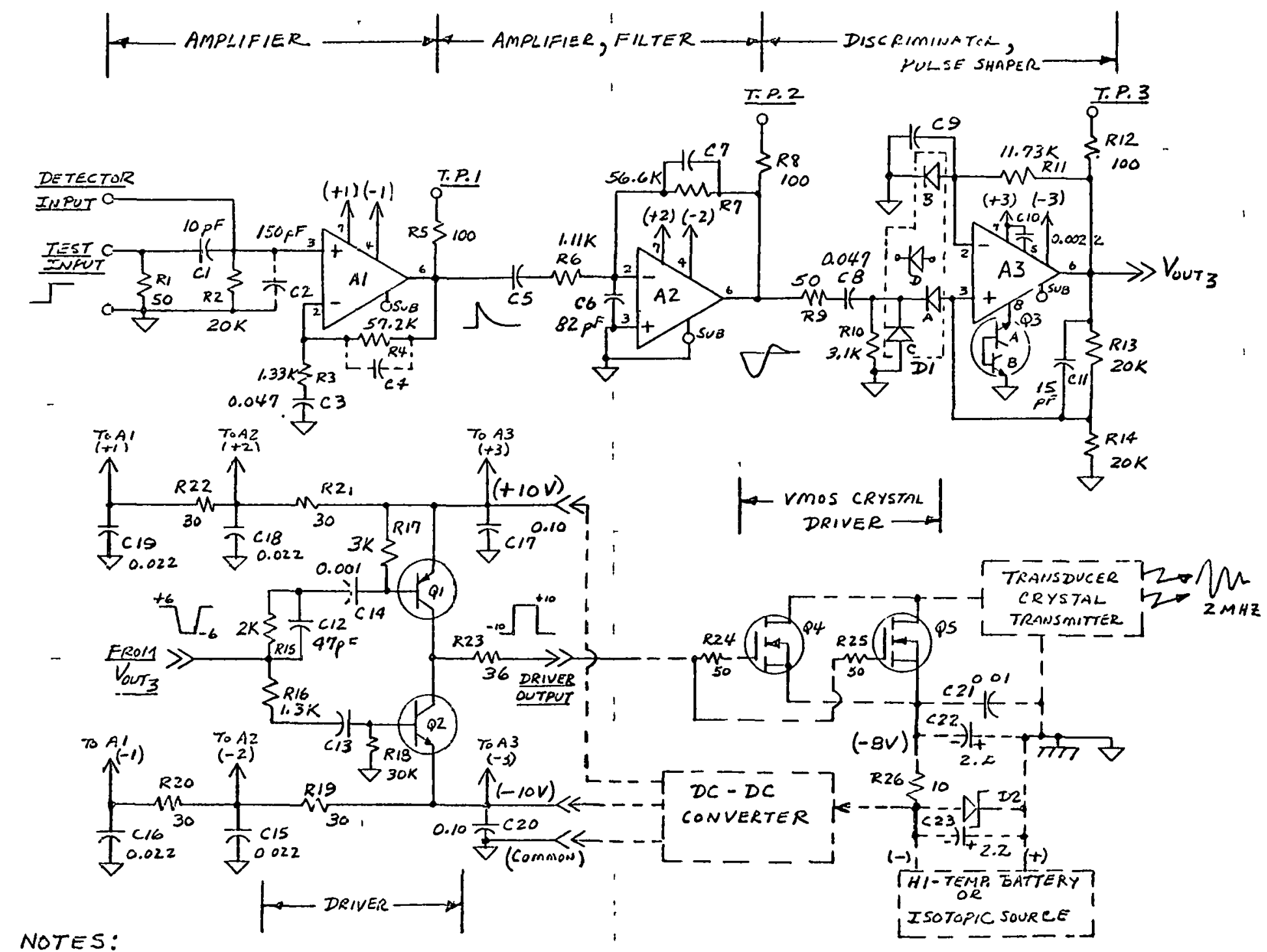

NOTES:

1. ALL RESISTIRS IN OHMS; ALL CAPACIICAS IN MICROFARADS, UNLESS OTHERWISE STATED.

2. $A 1, A 2, A 3=H A 2625 ; Q 1=2 N 3406 ; Q 2=2 N 3904 ; Q 3=D I 3424$ or $2 N 3563 ; Q 4,05=V N 0106 N 2 ;$

$D /=D I S / 4-1 Q ; D 2=I N 297 / 2 R$ (rioToRSLA)

3. CSANB CI3 CHOSEN FOR OUTPUT, PULSE WIDTH.

Figure 3-4. Schematic diagram of op-amp Circuit III. 


$$
V_{\text {node } 3}=\frac{(R 10)\left(V_{\text {Out }_{3}} / 2\right)+V_{D I A}(R 13|| R 10)}{[(R 13|| R 10)+R 10]},
$$

or substituting values, at $25^{\circ} \mathrm{C}, \mathrm{V}_{\text {node }} 3 \approx+1.2 \mathrm{~V}$. Thus, the discriminator trigger level is $-\left(v_{\text {node }} 3-v_{\text {node } 2}\right)$ or $-0.6 \mathrm{~V}$ at room temperature. The change of the trigger level with temperature is dependent primarily upon the temperature tracking of $V_{D 1 A}, V_{D 1 B}$, and the temperature coefficient of $\mathrm{V}_{\text {out }}$. Taking the differentials involved with respect to temperature gives

$$
\begin{aligned}
\frac{\Delta V_{\text {trigger }}}{\Delta T} & =\frac{\Delta\left(V_{\text {node } 3}-V_{\text {node } 2}\right)}{\Delta T} \\
& \approx \frac{R 10 / 2}{[(R T 3|| R T 0)+R T 0]}\left(\frac{\Delta V_{\text {out }}}{\Delta T}+2\left|\frac{\Delta V_{D 1}}{\Delta T}\right|\right)
\end{aligned}
$$

where it is assumed that $\Delta V_{D 1 A} / \Delta T=\Delta V_{D 1 B} / \Delta T$ and the diode temperature coefficient (T.C.) is negative. Thus, the trigger level will be constant for increasing temperature if the $V_{\text {out }}$ level has a negative T.C. of twice the value for $V_{D I}$. Also, if the current in DIB is greater than that in DIA, this will help to provide cancellation of T.C. values. Transistor Q3A-Q3B is utilized as a low-capacitance sharp-breakdown Zener clamp $\left(V_{Z} \approx 6.2 V\right)$ with a negative T.C. The voltage at node 8 of $A 3$ is the same as the output voltage. Diode DIC is normally not conducting, but is used as a clamp for large negative output signals from A2. Discriminator $A 3$ has considerable Schmitt feedback (by R13, R14, and $\mathrm{CI1}$ ) so that once triggering occurs the diode DIA is reverse biased by a level of $-\left(\mathrm{V}_{\text {out }_{3}} / 2\right)$, or approximately $-3.1 \mathrm{~V}$. Thus, false triggering by transient feedback of the output pulse signal is prohibited. 
The output pulse width $T$ of $A 3$ is controlled by the charging of C9 through R11. The pulse-width equation for the discriminator can be derived as

$$
T=\operatorname{Ri1C9} \ln \left(\frac{v_{\text {out }_{3}}+V_{\text {DIB }}}{V_{\text {out }_{3}}{ }^{/ 2}}\right)
$$

* RIIC9 en $2.2=0.79$ RIIC9.

For the values of $\mathrm{R} 17=11.7 \mathrm{~K}, \mathrm{Cg}=470 \mathrm{pF}, \mathrm{V}_{\text {out }_{3}}=6.2 \mathrm{~V}$ and $\mathrm{V}_{\mathrm{D} I \mathrm{~B}} \approx 0.6 \mathrm{~V}$ used in the prototype circuit, the design value for $T$ is $4.3 \mu \mathrm{sec}$. The measured value was $5 \mu \mathrm{sec}$, with the increase due to finite slewrate 1 imits of the rise-and fall-times of $A 3$.

The significant added feature of Circuit III compared to Circuit I is the inclusion of the Q1-Q2 driver circuit. In this circuit transistor $Q 2$ is normally conducting (and saturated) at $\mathrm{I}_{\mathrm{B} 2}=\mathrm{I}_{\mathrm{C} 2}=0.3 \mathrm{~mA}$, while $Q 1$ is in the non-conducting state. The negative leading-edge of the output signal from the discriminator $\left(\mathrm{V}_{\text {out }}{ }_{3}\right)$ will turn-off Q2 and turn-on Q1. This complementary switching action provides very fast rise-and fall-times for the output signal to drive the high capacitance input gates of Q4-Q5. Since current is only furnished during the transition states, the quiescent current drain of Q1-Q2 is low.

As an example of the high current output drive conditions of Q1-Q2, the total emitter currents and output voltage signal is shown in Fig. 3-5 for a total simulated load (gate input capacitance of Q4-Q5) of $490 \mathrm{pF}$. The values of $\mathrm{C} 9$ and $\mathrm{C} 73$ were changed to obtain an output pulse width of $1.8 \mu \mathrm{sec}$ for this Figure. 


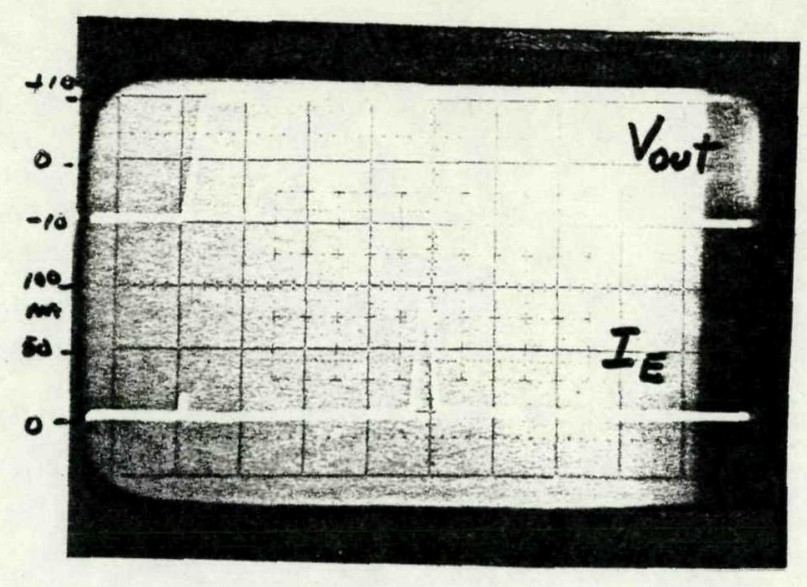

(a) Emitter current of Q2 (2N3906), and $V_{\text {out }}$.

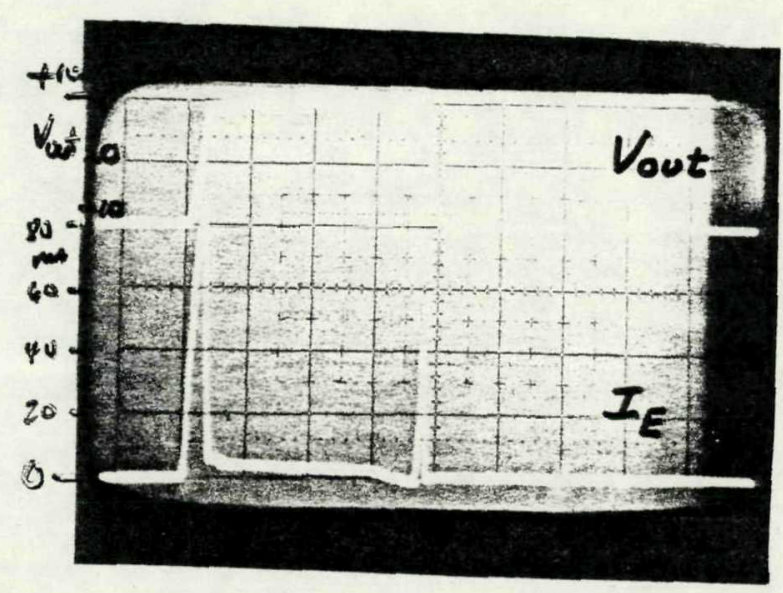

(b) Emitter current of Q1 (2N3904), and $V_{\text {out }}$.

Figure 3-5. Output signal voltage and currents for the driver stage of Q1-Q2, with $C_{L}=490 \mathrm{pF}$. The time scale is 0.5 psec/div. 


\section{3-2 Circuit III Construction and Operation}

In Fig. 3-6 is the hybrid thick-film layout for Circuit III. This circuit was constructed on a 1.25 inch $\times 1.25$ inch ceramic substrate. A photograph of the experimental circuit mounted on a test circuit board is shown in Fig. 3-7.

The circuit was placed on test the latter part of August, 1980, and has been operating at $230^{\circ} \mathrm{C}$ since that time. To date approximately 700 hours of operation have been accumulated. Some of the results, and comparisons with Circuit I (Fig, 3-4) are described below.

(1) As described in Section 3.3-1, the discriminator trigger level was temperature compensated. There was no observable (within $\pm 50 \mathrm{mV}$ ) change in the trigger level for the operating circuit from $25^{\circ} \mathrm{C}$ to $230^{\circ} \mathrm{C}$. The output pulse width from $\mathrm{A} 3$ increased from $5 \mu \mathrm{sec}$ at $25^{\circ} \mathrm{C}$ to $6.4 \mu \mathrm{sec}$ at $230^{\circ} \mathrm{C}$.

(2) A11 dc output voltage levels remained within $\pm 10 \mathrm{mV}$ for op-amps $A 1$ and $A 2$ while the output level at $A 3$ decreased slightly due to the negative T.C. of Q3.

(3) The gain change for the input test signal to the output of A3 was less than $5 \%$. Pulse shapes remained essentially identical to thase at $25^{\circ} \mathrm{C}$.

(4) The driver circuit was notable in performance, with output rise-and fall-times into a simulated $350 \mathrm{pf}$ load of $<100 \mathrm{nsec}$, with a drive to within $100 \mathrm{mV}$ at either power supply.

(5) Two problems were encountered with the test circuit. An oscillation developed in the $\mathrm{A} 2$ amplifier at $\sim 210^{\circ} \mathrm{C}$ due to changes in the high temperature loop transmission. This is easily corrected by increasing the value of $\mathrm{C} 6$. The second 


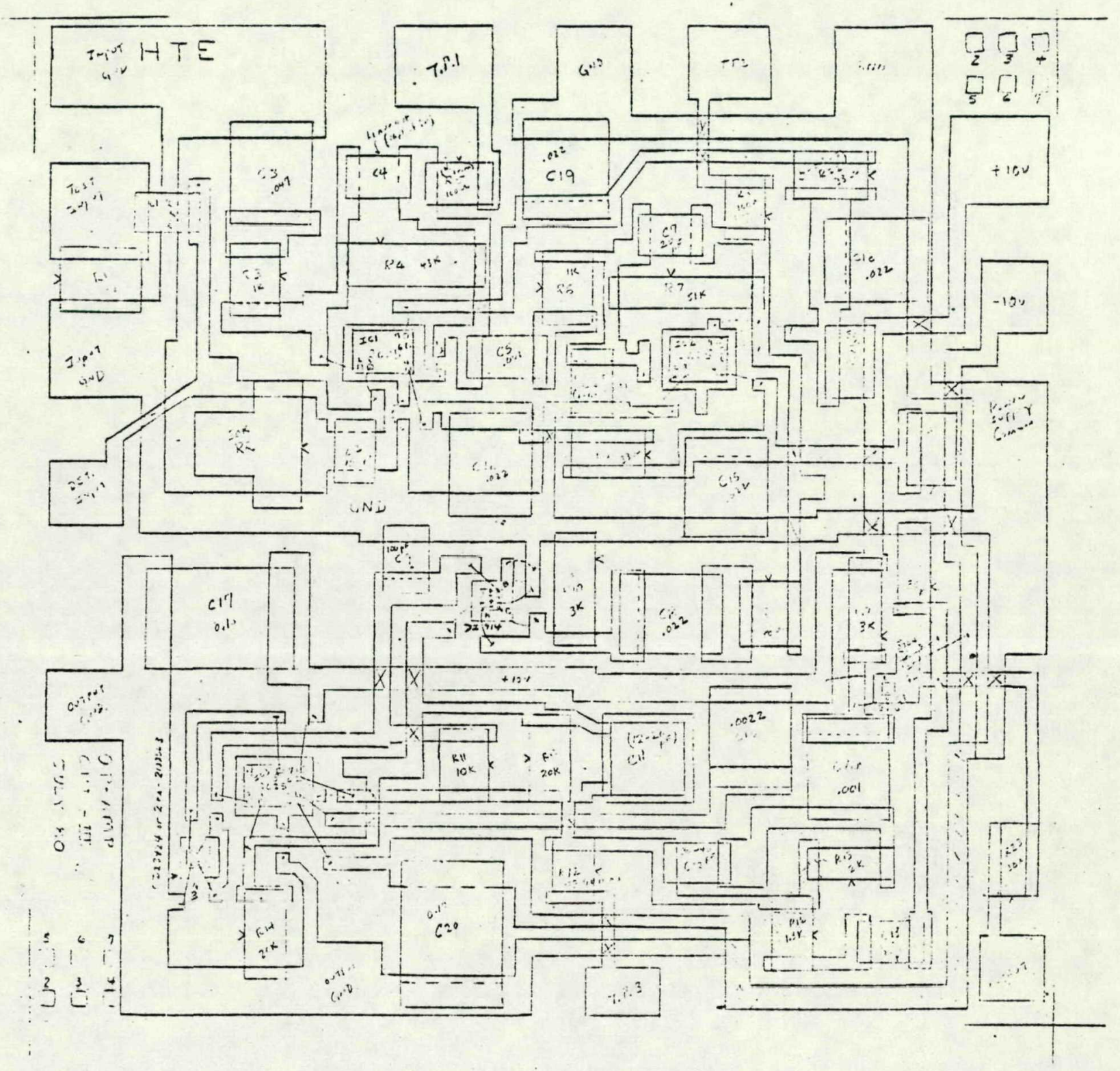

Figure 3-6. Thick-film hybrid layout for op-amp Circuit III. Overall substrate size is 1.25 in by 1.25 in. 


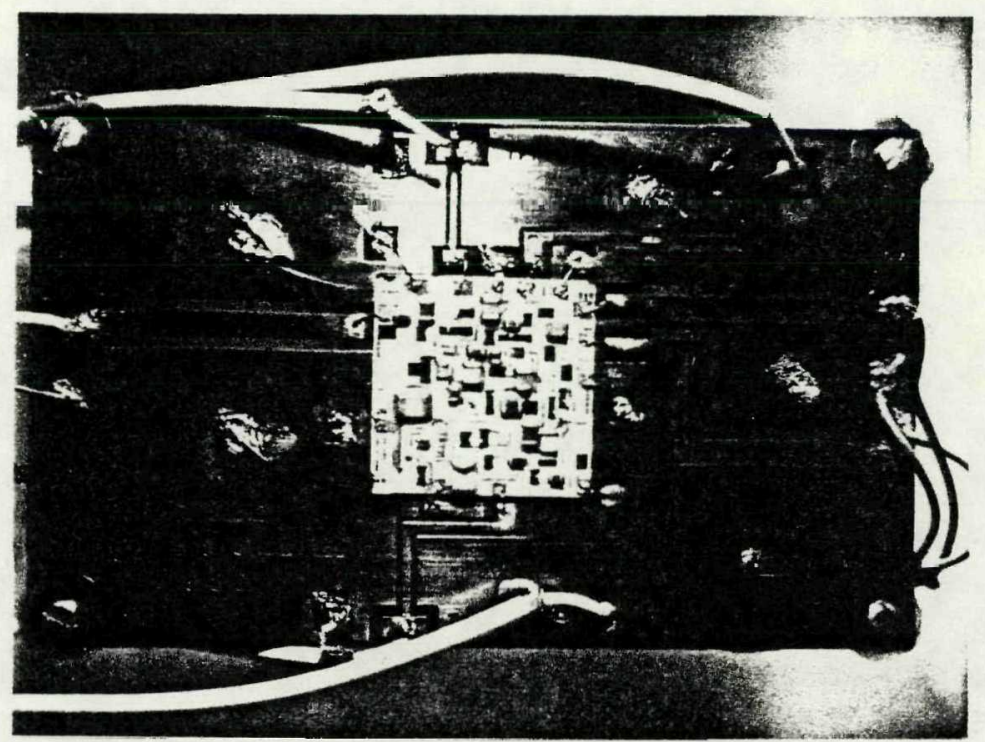

Figure 3-7. Circuit test board for Circuit III. 
problem was due to the layout of the hybrid circuit.

Capacitors $\mathrm{C} 17$ and $\mathrm{C} 20$ were not closely coupled to driver transistors $Q 1$ and $Q 2$. This resulted in feedback of fast transients that distorted the output pulse at A2. Since the discriminator had already triggered, this distortion has no effect on system performance.

\section{3-3 Sumnary}

Results of the high temperature tests indicate that Circuit III is adequate for use for initial fuel loading requirements. The discriminator and output driver circuits are improvements over those of Circuit I. However, in our opinion the slight decrease in the number of wire-bonds and the decrease in operating current for Circuit III is not sufficient reason for changing from the use of Circuit I. It does provide us with an alternative circuit concept for perhaps later usage. 


\section{CHAPTER 4}

\section{RADIATION EFFECTS}

\subsection{INTRODUCTION}

For initial fuel loading of the CRBR the radiation environment is generally low, with a gamma dose rate anticipated to be less than $1 \mathrm{r} / \mathrm{hr}$, for a total accumulated dose of less than $2 \times 10^{3}$ rad. Similarly, the neutron flux is anticipated to be less than $10^{5} \mathrm{n} / \mathrm{cm}^{2} / \sec (\mathrm{nv})$, or a total dose less than than $10^{12}{ }^{1}$ nvt .

The fuel reloading requirements are, however, much more severe. The anticipated neutron level is approximately $13^{10} \mathrm{n} / \mathrm{cm}^{2} / \mathrm{sec}(\mathrm{nv})$, or a total dose in the range of $10^{16}$ nvt, while the gamma rate is expected to be in the range $10^{4}-10^{6} \mathrm{r} / \mathrm{hr}$, or a total dose of $10^{7}$ tolo $\mathrm{rad}^{2}{ }^{2}$ Assuming that some shielding could be employed to reduce the radiation levels by a factor of 10 , we arrive at a radiation dose of approximately $10^{15}$ nvt (neutrons) and $10^{6}$ tol $10^{8}$ rads (gamma).

Since circuit requirements are much more severe for fuel reloading, we began radiation tests on several semiconductor devices that had been utilized in circuits designed over the last two years of contract research. Some of the preliminary results are presented in the following sections.

IPrivate communication wi th J. T. Delorenzo, ORNL, June, 1979. ${ }^{2}$ RST Review Meeting, OKNL, June 23, 1979. 


\subsection{THEORY}

Radiation damage to semiconductor devices for fuel reloading circuits is primarily due to the ionizing effects of gamma rays. The basic damage effects of ionizing radiation result from the uniform generation of electron-hole pairs. Photocurrents are generated in all reversebiased pn junctions, thereby increasing the leakage current of the device. Two effects of ionizing radiation on oxidized silicon surfaces are the buildup of a positive space charge within the oxide and the creation of fast surface states at the oxide-silicon interface resulting in increased surface recombination velocity.

Electrical characteristics are particularly sensitive to changes in the oxide passivation layer of bipolar devices and the gate isolation oxide of MOS devices. In the case of bipolar transistors, increases in fast surface states and charge buildup both lead to increased leakage currents and current gain $\left(h_{F E}\right.$ or $\left.\beta\right)$ degradation. For both $p-$ and $n-$ channel MOS devices, the threshold voltage $V_{T}$-the gate voltage required to induce an inversion layer between the source and drain regions thereby resulting in the flow of drain current - is shifted in the negative voltage direction due to the radiation induced buildup of positive space charge within the oxide.

Gamma radiation also causes displacement damage to semiconductor material by creating defects in the crystal lattice that introduce additional states in the energy gap. Displacement effects include increased current in reverse-biased pn junctions, decreased minoritycarrier lifetime, and decreased carrier mobility. Although not as significant as ionization effects, displacement damage also increases leakage currents and degrades current gain in bipolar devices. 


\subsection{RADIATION TESTS}

Several semiconductor devices (bipolar transistors, JFETs, MOSFETS, VMOS transistors, and IC operational amplifiers), capacitors, and thick-film resistor were irradiated at $1.3 \times 10^{5} \mathrm{rad} / \mathrm{hr}$. for a total dose of $1.8 \times 10^{7} \mathrm{rad}$. Evaluations were made, and all devices were then heated at $230^{\circ} \mathrm{C}$ for 136 hours, the initial irradiation time. A second test was performed, prior to the temperature annealing, to measure photocurrents in various devices while undergoing the $1.3 \times 10^{5}$ $\mathrm{rad} / \mathrm{hr}$. gamma radiation.

Gamma radiation was provided by a Cobalt -60 irradiator located in the Chemistry Department, UTK. AII test samples were irradiated within 90 percent of the geometric center in the irradiation chamber where the rated dose rate was approximately $1.3 \times 10^{5} \mathrm{r} / \mathrm{hr}$. Data for the evaluation of semiconductor devices were obtained utilizing the Tektronix 577 Curve Tracer, and the 178 Linear IC Test Fixture for operational amplifiers.

The first test was to evaluate damage resulting from $1.8 \times 10^{7}$ rads total dose (no bias voltage applied). All devices were characterized prior to and following the irradiation. Facilities at UTK did not allow concurrent heating to simulate the molten salt environment of $200-230^{\circ} \mathrm{C}$. A practical substitute was to heat the devices in an oven at $230^{\circ} \mathrm{C}$ for an equivalent time period after the radiation (hereafter refered to as annealing).

A second test was performed to measure the effects of ionizing radiation on leakage currents for various transistors. After receiving the total radiation dose the transistors were biased while inside the 
irradiation chamber and measurements made using external wire leads. Collector-to-base leakage current $I_{C B O}$ for bipolar transistor and gate-to-channel leakage currents $I_{\text {GSS }}$ for JFETs were measured with a reverse bias of 10 volts. VMOS transistors were tested for zero-gatevol tage drain current I DSS with 10 volts channel bias. Currents were also measured after removing the transistors from the irradiation and again after annealing.

\subsection{TEST RESULTS}

\section{4-1 Bipolar Transistors}

In general, the effects of the $1.8 \times 10^{7}$ rad gamma dose was to cause a current gain $\left(h_{\mathrm{FE}}\right)$ decrease, which was between 44 and 89 percent for the npn devices and 42-86 percent for the pnp devices. However, most of these effects were removed after annealing, with an $h_{F E}$ recovery to within 66-116 percent for npns and 55-101 percent for pnps. The least degradation occurred with high-frequency small-geometry devices.

Leakage currents $I_{C B O}$ due to photocurrent effects at $1.3 \times 10^{5}$ $\mathrm{r} / \mathrm{hr}$ were also evaluated on several devices. In some cases the increase in $\mathrm{I}_{\mathrm{CBO}}$ was over 1000 times the room temperature value, however all values were less than $10^{-8}$ amp, which is small compared to the high temperature values.

Changes in reverse breakdown voltages $B V_{C B O}$ and $B V_{E B O}$ were measured, with typically changes being less than 5 percent.

\section{4-2 JFETS}

Transconductance, breakdown voltage, pinch-off voltage, and drain saturation current were escentially unaffected by the irradiation. 
Gate-to-channel leakage currents $I_{G S S}$ were comparable to $I_{\text {CBO }}$ for bipolar transistors with the larger geometry devices having the larger currents.

\section{4-3 VMOS Transistors}

The N-channel Supertex VMOS (VN0106) had a shift in threshold voltage $V_{T}$ from an initial +1.5 volts to -2.0 volts due to the total dose irradiation. After annealing $V_{T}$ recovered to +1.0 volts. Transconductances for drain currents above one ampere were considerably lower after irradiation with little recovery after annealing. There was less than 10 percent variation in low-channel ON-resistance and no change in breakdown voltage. Due to the polarity change in $v_{T}$, zero gate-voltage drain current could not be measured after irradiation.

The P-channel Supertex VMOS (VP0104) had a shift in $V_{T}$ from an initial -1.76 volts to -0.77 volts after annealing. Transconductance was essentially unaffected, but channel breakdown voltage decreased from 57 volts to 26 volts with no recovery after annealing. This latter effect, was not expected, and has yet to be resolved.

\section{4-4 Operational Amplifiers}

Characteristics of the HA-2625 (single) and the HA-4625 (quad) op amp were evaluated before and after irradiation, and after annealing. The Ha-4625 amplifier ceased to function after irradiation, and only partially recovered after annealing. The HA-2625 op amp was still functional after irradiation, but with considerable degradation of operating parameters. After annealing partial recovery was obtained, but with an approximately $40 \%$ reduction in the gain-5andwidth product. 
Both op amps employed dielectric isolation construction.

\section{4-5 Thick-Film Resistor Inks}

There were some shifts in thick-film resistor values, depending on manufacturer and the ohms/square resistivity of the ink. The inks we are currently using (Dupont 1600 series) indicated the following general trends after irradiation and annealing: The $100 \mathrm{ohm} / \mathrm{square}$ (DP1621) indicated a worst-case drift of $+5.6 \%$ with a mean of $+1.5 \%$. The $1 \mathrm{~K} \mathrm{ohm} / \mathrm{square}$ (DP1631) had a worst-case of $+1.1 \%$ and mean of $+0.51 \%$. The 10K ohm/square (DP1641) had values of worst-case of $+1.97 \%$ and mean of $+.70 \%$, while the $100 \mathrm{~K} \mathrm{ohm} / \mathrm{square}$ (DP1651) had worst-case of $+1.3 \%$ and mean of $+0.7 \%$. In general the Dupont 1600 inks were the best of those tested.

\section{4-6 0ther Devices}

Three zener diodes (1N2971B, 1N4104, and 1N5239B) and the DI914-1Q small-signal diode were irradiated and annealed with essentially no changes in characteristics.

Results on capacitors indicated no significant change in value. Leakage currents showed complete recovery after annealing for the Phillips and USCC types used in the circuits. One CMOS IC tested (CD4007) had $V_{T}$ values of $|1.3 \mathrm{~V}|$ initially, and values of $-10 \mathrm{~V}$ ( $P$-channel) and $<0 V(N-c h a n n e l)$ after irradiation. Annealing destroyed the epoxy case of the CD4007. 


\subsection{SUMMARY}

Initial radiation tests on devices indicate that, with annealing anticipated at the $230^{\circ} \mathrm{C}$ operating temperature, circuits suitable for the fuel reloading environment should be feasible. However, the combined simultaneous effects of both temperature and radiation on operating devices must be more seriously evaluated, as must also the effect of neutron irradiation.

Statistical data from a larger population of each device must also be obtained before an accurate model of irradiation effects can be constructed. However, the outlook from the preliminary data obtained so far is certainly encouraging. 


\section{CHAPTER 5}

\section{MISCELLANEOUS RESEARCH}

\subsection{INTROOUCTION}

This chapter covers various studies and research work conducted under the past years contract that are not directly connected with the amplifier or discriminator development. Such items as capacitor tests, comparisons of aluminum - $7 \%$ silicon wire versus aluminum $0.5 \%$ magnesium wire for high temperature ultrasonic bonds, computer programs for high-temperature simulations, and evaluation of new thickfilm conductors for high temperature solderability and silver migration effects are discussed in the next several sections.

\subsection{CAPACITOR TESTS}

Several tantalum chip capacitors from Union Carbide Corporation (Kemet" capacitors), Mepco-Electra and Sprague were tested for use at $230^{\circ} \mathrm{C}$. The Mepco-Electra and Sprague chips were found to have a gold metallized end cap which was attached with a low temperature solder (M.P. 220 $\mathrm{C}$ ); therefore, these capacitors were not tested further.

The "Kemet" capacitors, however, had high-temperature connections of the electrodes and are useful for $230^{\circ} \mathrm{C}$ operation. For ease of attachment, the standard epoxy encapsulated chips were evaluated. The capacitors were tested at $230^{\circ} \mathrm{C}$, with 10 VDC applied, and with a simulated $100 \mathrm{~mA}$ (at $100 \mathrm{kHz}$ ) pulse current. Except for one solder connection to an external lead that opened at 1500 hours, all other capacitors functioned well for the 2200 hours period of the tests. The dc leakages through the capacitors are shown in Fig. 5-1, along 


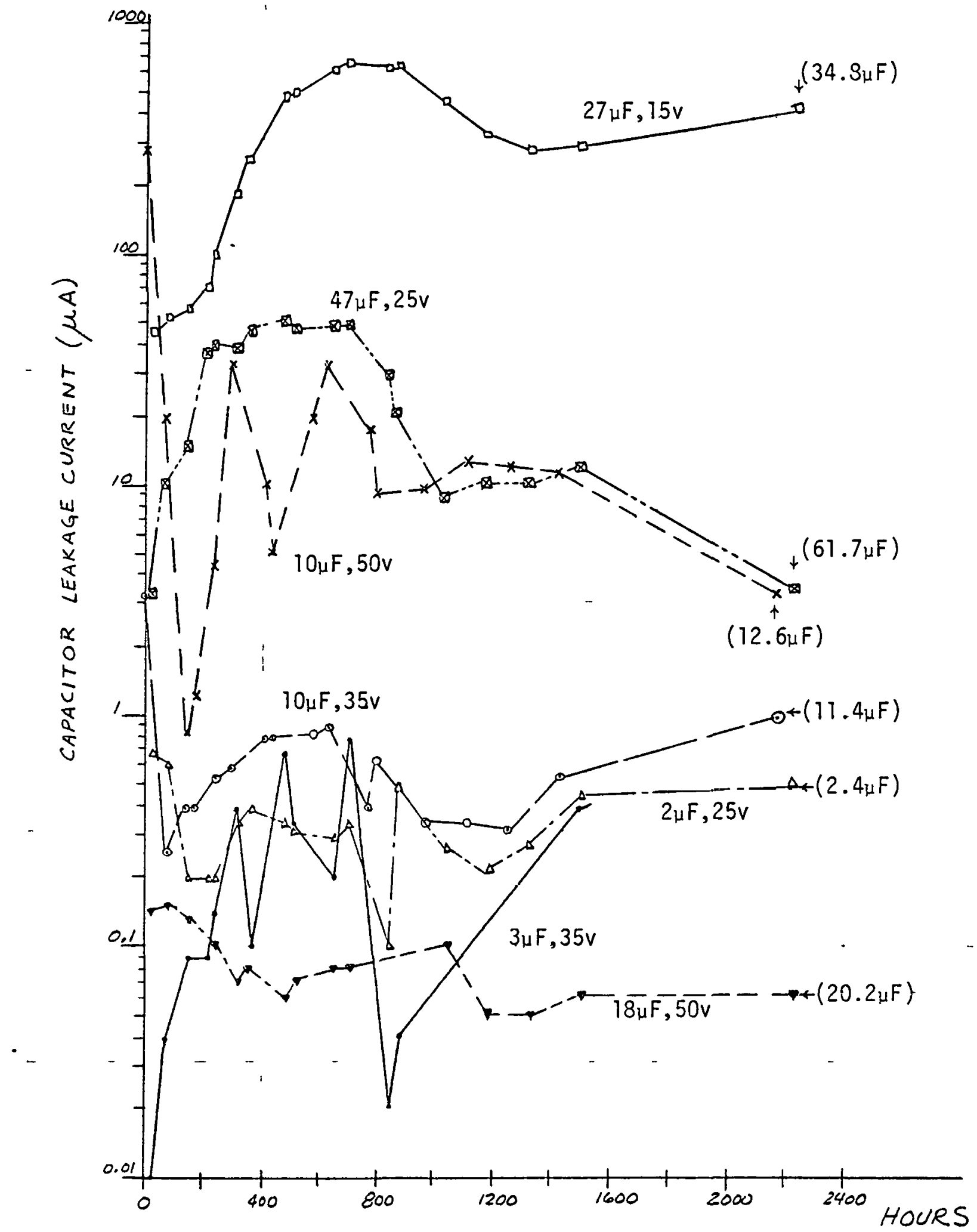

Figure 5-1. Long-term test data for "Kemet" tantalum capacitors at $230^{\circ} \mathrm{C}$. Tested at 10 VDC and $100 \mathrm{~mA}, 100 \mathrm{kHz}$, pulse current applied. 
with the final measured capacitance values. Generally, the data indicates that for $230^{\circ} \mathrm{C}$ operation one should use low values of capacitance $(\leq 10 \mu \mathrm{F})$ with the largest voltage rating.

Various ceramic capacitors from Spraque, Mepco-Electra, and Johannson were evaluated for use at $230^{\circ} \mathrm{C}$. Previously, we had utilized capacitors from USCC (U'S Capacitor Corp.) in designs during last years contract period. Although no significant long-term tests were performed, initial results from short-term tests ( $<200$ hours) indicated that the larger $0.1 \mu \mathrm{F}$ Sprague capacitor (which has an increased dielectric thickness as compared to the USCC unit) is perferred for high-temperature use. Another favorable feature of the Sprague capacitors is that they are readily available with a 10/90 solder coating. These capacitors employed the standard X7R formulation. We have never had a failure with an NPO formulation capacitor from any of the manufacturers.

5.3 COMPARISONS OF ALUMINU:1 WIRE FOR HIGH-TEMPERATURE ULTRASONIC BONDS We performed tests on various thick-film conductors* (Pd Ag, Pt Ag, Au) ultrasonically bonded with 1-mil (25 micrometers) aluminum - $1 \%$ Si wire as compared with $1-m i l$ aluminum $-0.5 \%$ magnesium wire. The bonder used was a K\&S Model 484 ultrasonic bonder. Bonds were also made on several semiconductor chips (No. 1 bond on the chip) and with the No. 2 bond on the particular thick-film conductor. The Al-1\% Si wire

*The following conductors were evaluated; Englehard A 2763 ( $\mathrm{Au}$ ), EMCA 4249 (Pt Ag), Englehard A 2472 (Pd Ag), DuPont 9910 ( $\mathrm{Au}$ ), DuPont 6120 $(P d \wedge g), A V X$ 6050A (Pd Ag), AVX 6750A (Pd Ag), AVX $3516(\mathrm{Au})$, ESL $9633 \mathrm{~B}$ $(P d A g)$. 
was manufactured by Secon Corporation, and had an elongation of $3 \%$, whereas the $\mathrm{Al}-0.5 \% \mathrm{Mg}$ wire had an elongation of $2-3.5 \%$, and was from Cooper Division, Sterndent Corporation. A11 bonds were aged at $230^{\circ} \mathrm{C}$ for a period of 170-250 hours. Bond pull tests were performed on each bond utilizing an Orthodyne pull-tester. The essential results were the following:

(1) For all conductors tested, the $\mathrm{Al}-0.5 \% \mathrm{Mg}$ wire gave an improvement over the $\mathrm{Al}-1 \% \mathrm{Si}$ wire in aged pull strength of approximately $15-20 \%$. The wire breakage was invariably at the heel of the No. 1 bond.

(2) The best aged adhension was with the Pt-Ag conductor (EMCA 4249) with typical pull strengths with A7-0.5\% Mg wire of 6-8 gm (other researchers have recently indicated a possible increase in contact resistance with $\mathrm{Pt}-\mathrm{Ag}$ bonds, however). The second best conductor material was either DuPont 9910 or AVX 3516, both mixed-bonded Au conductors, with A7 $-0.5 \% \mathrm{Mg}$ wire pull strengths of 5-7.5 gm after aging.

(3) The wire bonds (No. 1 bond) on the aluminum pads of the semiconductor chips were excellent, even after aging. Using $\mathrm{Al}-0.5 \% \mathrm{Mg}$ wire the breakage on the No. 1 bond was always at the heel, with no failures due to bond liftoff.

\subsection{COMPUTER PROGRAMS FOR HIGH-TEMPERATURE SIMULATIONS}

During the contract period two computer programs were obtained for modeling of high-temperature effects in semiconductor circuits. SPICE 2, originally developed by the University of California in 1975, is most directiy applicable since it was developed primarily for 
modeling monolithic amplifiers. A key feature of this program is the ability to vary device operating temperature. This program was added to the UTK computer system in January 1980. We have an M.S. Thesis currently underway to collate all user information and prepare a tabular listing of SPICE parameters for those semiconductor devices of most use for high-temperature circuits.

The program tape for SUPER SCEPTRE was also obtained. This program is an update by the University of Florida of the much older version of SCEPTRE by IBM. This program has not yet been utilized, since it requires more static memory allocation than SPICE, and also is not as versatile for semiconductor analysis. The key features of SUPER SCEPTRE are a systems analysis capability, and more detailed analys is of radiation effects. In fact, the original program was directly intended for

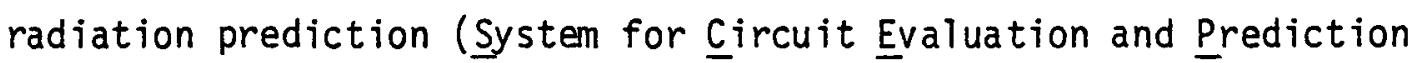
of Iransient Radiation Effects).

\subsection{SILVER MIGRATION AND SOLDERABILITY OF VARIOUS THICK-FILM CONDOCTORS}

The most convenient solder for assembling our circuits has been a $10 / 90$ formulation ( $10 \% \operatorname{tin}, 90 \%$ lead) which has a melting point of $300^{\circ} \mathrm{C}$. Early tests had shown, however, that this solder is not compatible with the DuPont 9910 gold conductor utilized in most of the high temperature circuits. In effect, at high temperatures the tin scavenges the available gold until equilibrium is reached. One of the failures of the tests at ORNL was, in fact, due to a gold conductor removal in the $D C-D C$ Converter I circult by an overflow of $10 / 90$ solder. Thus, it became apparent that a two-cionductor system was necessary; a mixed-bonded gold conductor (such as DuPont 9910 or 
AVX 3516) for low resistance and good aluminum wire bondability, and a second conductor with good solderability.

The various manufacturers of thick-film inks were contacted for their recommendations of a good high-temperature solderable conductor. Samples were obtained from most manufacturers and evaluated. The following inks were tested: Englehard A2472 (Pd-Ag), Englehard A2475 (Pd-Ag), Englehard E682-A (Pt-Au), EMCA 4249 (Pt-Ag), EMCA $6095 \mathrm{~S}$ (Pd-Ag), ESL 9633-B (Pd-Ag), AVX 6050A (Pd-Ag), AVX 6750A (Pd-Ag), DuPont 6120 (Pd-Ag), DuPont 9770 (Pt-Ag), DuPont 9755 (Pd-Ag), DuPont 4093 (Pd-Pt-Ag), DuPont 9596 (Pt-Au) and DuPont 9885 (Pt-Au).

On all silver conductors tested a silver migration "water drop" test was performed in addition to solder adhesion. The "water drop" test involved an applied electric field between adjacent 1 ines of $2 \mathrm{~V} / \mathrm{mil}$ (typically, this was $20 \mathrm{~V}$ between two lines $10 \mathrm{mils}$ apart), with a drop of distilled water covering the lines. The current flow was monitored as well as observation of dentril formation under microscopic viewing .

The general results of these tests were as follows:

(1) All of the conductors suitable for soldering with $10 / 90$ solder were very poor when ultrasonic wire-bonding with $1-\mathrm{mil}$ wire was attempted. These conductors have a high percentage of $\mathrm{Pt}$ and/or Pd that prohibits good uitrasonic bonding. Thus, a two-conductor system is essential, with a mixed-bonded gold in areas where wire-bonds are necessary, and overlapped with another conductor for areas where soldering is necessary. 
(2) All of the conductors suitable for soldering have higher resistivity than standard gold or silver conductors. Most of these conductors were in the range of 0.04 to 0.08 ohms/ square, whereas standard Au or Pd-Ag conductors are typically less than 0.02 ohms/square.

(3) The best Pd-Ag conductors for soldering were DuPont 4093 (0.044 ohms/square) and ESL 9633-B (0.02 ohms/square). Both had a total current less than $0.1 \mathrm{~mA}$ after 5 minutes under the water drop test.

(4) The most reliable overall system (but the most expensive) would be to el iminate silver entirely, by using DuPont 9910 $\mathrm{Au}$ in the wire bond areas and overlap with Dupont $9596 \mathrm{Pt}-\mathrm{Au}$ in soldered areas. The Pt-Au conductor had no migration and had essentially the same high temperature pull strength as the best Pd-Ag ink, even after we irradiated the sample to $1.3 \times 10^{7} \mathrm{rad}$, and aged at $230^{\circ} \mathrm{C}$ for greater than 150 hours. The resistivity of the DuPont 9596 conductor is high, approximately 0.08 ohms/square. 


\section{LIST OF REFERENCES}

[1] E. J. Kennedy, T. V. Blalock, J. Phelps, R. Rochelle, and F. Dyer, "Research in Remote Signal Transmission Electronics," TR-EE/EL-10, ORNL/Sub-7644/10, Oct. 1, 1979. 